Portland State University

PDXScholar

$1-1-2010$

\title{
Do Parents Matter? Parental Attachment and Its Effect on Becoming Independent in Emerging Adulthood
}

Cara Joy Copeland

Portland State University

Follow this and additional works at: https://pdxscholar.library.pdx.edu/open_access_etds Let us know how access to this document benefits you.

\section{Recommended Citation}

Copeland, Cara Joy, "Do Parents Matter? Parental Attachment and Its Effect on Becoming Independent in Emerging Adulthood" (2010). Dissertations and Theses. Paper 102.

https://doi.org/10.15760/etd.102

This Thesis is brought to you for free and open access. It has been accepted for inclusion in Dissertations and Theses by an authorized administrator of PDXScholar. Please contact us if we can make this document more accessible: pdxscholar@pdx.edu. 
Do Parents Matter?

Parental Attachment and Its Effect on Becoming Independent in

Emerging Adulthood

by

Cara Joy Copeland

A thesis submitted in partial fulfillment of the requirements for the degree of

Master of Science

in Sociology

Thesis Committee:

Martha Balshem, Chair

Daniel Sullivan

Lindsey Wilkinson

Portland State University

2010 


\begin{abstract}
Data from the National Longitudinal Study of Adolescent Health Waves I and III are used to estimate the effect of parental attachment on independence in emerging adults ages 18 to 27 . The nature of independence focused on living in a place of their own, which described about half of the sample. The study finds that emerging adults who, in their youth, expressed high attachments to their parents, were slightly less likely to become independent as emerging adults. Rather, age and gender are greater positive predictors of independence.
\end{abstract}




\section{DEDICATION}

Dedicated to: Andy and my children: Jack, Henry and Lily. To my parents, Gary and Lydia Windom, to whom I am securely attached.

Andy, without your unfailing support and encouragement, this thesis would not have been possible. Thank you for all the times you have kept life going in my absence and for believing I could do this and so much more. Now it's your turn to soar while I pick up the slack! 


\section{ACKNOWLEDGEMENTS}

Without the help and support of others this project could not have been attempted or completed. Each group that follows has generously assisted me through the thesis process, which has included, but not limited to, providing time, expertise, advice, as well as every other kind of support I have needed.

1. Thesis Committee

1. Martha Balshem (co-chair): If it weren't for you, I would have quit this program long ago. You have been my biggest fan and challenged me to remember the big picture. Thanks for caring about me as both a scholar and a person.

2. Daniel Sullivan (co-chair): You gave crucial guidance in both the methods and overall conceptualization of my project.

3. Lindsey Wilkinson: Thank you for your availability to meet with me when I had questions or concerns. Your insights have proven fruitful in my final product.

2. Sociology Department

1. Thank you for providing me an opportunity to spread my wings in the field of Sociology. You have given me a good understanding of 
both quantitative and qualitative research. Special thanks to Drs. Hyeyoung Woo and Melissa Thompson for their consultation on this thesis.

2. A huge thank you to Dr. Richard Settersten of Oregon State University. You let me call, email, and even visit to glean your expertise. I respect your work and appreciate your generosity.

3. Family \& Friends

1. Andy - Feigning interest in my incessant need to verbally process everything I was learning. Reading my work and asking good questions. Most of all, giving me the space to get this done.

2. Kids - Jack, Henry \& Lily. Thanks for being my inspiration!

3. My Village - You have cared for my children, cleaned the house, given me laughter, kept me focused and generally made life bearable in this season. Thanks Rachel, Kate, Erinn, Martha, Marta, Kayla, Tamara, Jill, and Sarah! 


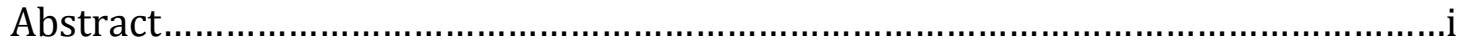

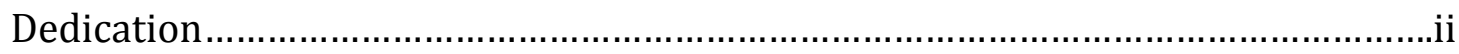

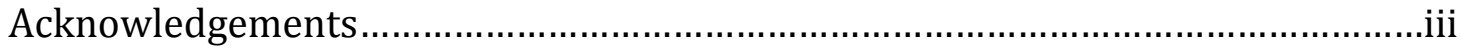

List of Tables.................................................................................................

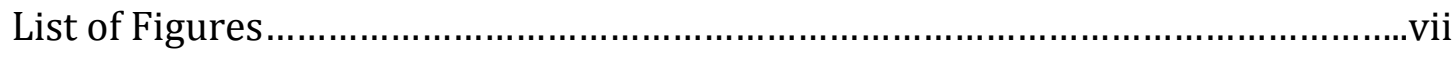

Chapter I

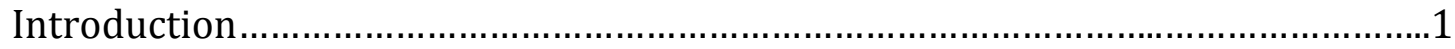

Chapter II

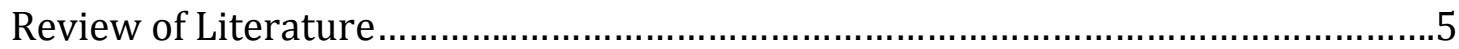

Chapter III

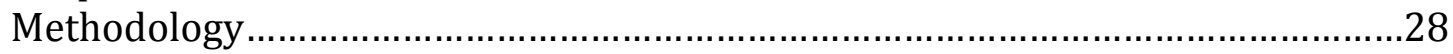

Chapter IV

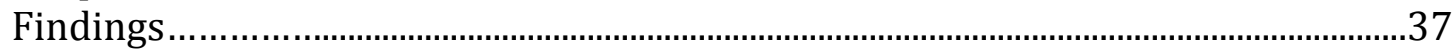

Chapter V

Discussion and Conclusion.................................................................................................51

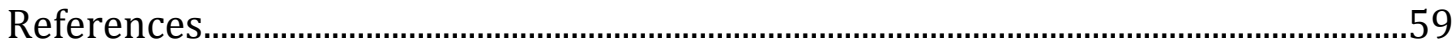

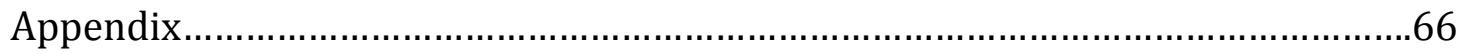




\section{LIST OF TABLES}

Table 3.1 Descriptive Statistics for All Variables..............................................35

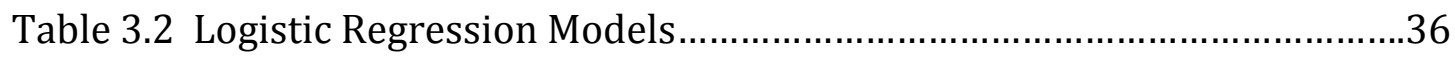

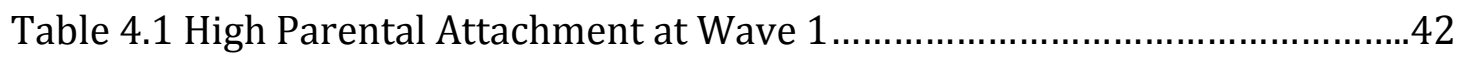

Table 4.2 Independence, by All Independent Variables..................................44

Table 4.3 Estimated Odds Ratios Predicting Independence ...............................50 


\section{LIST OF FIGURES}

Figure 2.1 The Push and Pull Factor: Attachment and Control Working

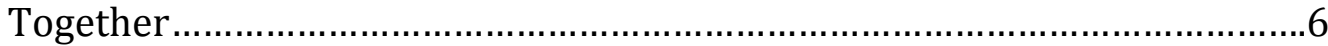

Figure 2.2. Social Forces and Parent-Child Relational Variability........................18

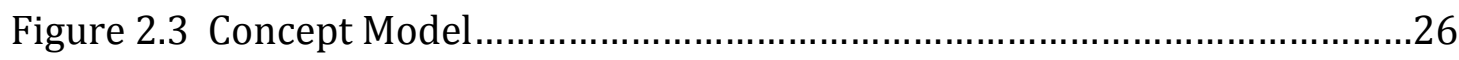

Figure 4.1 Comparative Parental Attachment Percentages.................................37

Figure 4.2 Parental Attachment, by Family Education .....................................40

Figure 4.3 Living Arrangements of Emerging Adults ....................................43

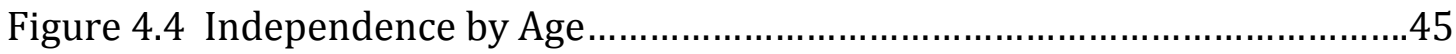




\section{CHAPTER I}

\section{INTRODUCTION}

According to statistics, emerging adults are becoming independent much later than they did fifty years ago (Furstenberg, Kennedy, Mcloyd, Rumbaut and Settersten 2004). The 2000 census indicates that $25 \%$ of young adults ages 18 to 34 still live with their parents. Previous studies have described various reasons for this prolonged departure into adulthood, including changing gender norms and differences in the economic condition of today's world (Fussell and Furstenberg 2005). What is not clear is the affect that parents or guardians have on the timely transition to adulthood of their children. Why are more children remaining in the nest instead of independently flying away? What are the common characteristics of individuals who have not become independent? Could the parents of these young adults be part of the solution? The purpose of this study is to determine whether or not the relationship an emerging adult has with his or her parents is a predictor of becoming independent by age twenty-seven.

Researchers measure adulthood using five traditional benchmarks: leaving home, finishing school, getting married or being in a committed relationship, becoming a parent, and being financially independent. In a review of U.S. Census 2000 data, Furstenberg et al. found that by age 30, only $46 \%$ of females and $31 \%$ of males had achieved all five markers (2004). This is in stark comparison to the $77 \%$ of females and $65 \%$ of males the same ages who had completed these markers in 1960 , 
according to U.S. Census data from that year (Furstenberg et al. 2004). Times have changed and researchers are tracking the evolution of a new generation. This generation is giving new definitions to both the conceptualization of adulthood and the time frame for achieving it.

Why is being independent favorable?

While the rest of life seems to be picking up pace, becoming an independent adult is the one element that is slowing, and we should be thankful, right? While some may argue that there is no need to hurry into the future, this lengthening of youth is having negative consequences on the social institutions that are supporting these emerging adults. Families continue to be the primary supporters of emerging adults who have not yet launched into independence. Schoeni and Ross (2004) estimate that $25 \%$ of the cost of raising a child is incurred after he or she reaches age 17 . This same study shows that about $40 \%$ of older emerging adults are still receiving some sort of financial support from their family. This financial strain is added to the burden of living in a period of economic downturn. Frequently, these same families are also shouldering the burden of supporting aging parents who are living longer, often outliving their own pensions.

What is affecting becoming independent?

Research indicates that this transition to independence is affected by a variety of forces (Fussell and Furstenberg 2005). Social class has an influence on this process (Mollenkopf, Waters, Holdaway and Kasinitz 2005; Osgood et al. 2005; Fussell and 
Furstenberg 2005). Prolific research in the social sciences has recounted the additive value of being born into a higher class. In pure economic terms, families with more financial resources are better able to get their children the education they need to be financially independent in the current economy.

Class and race are two variables that are inextricably linked on multiple levels. When considering race as a factor that might impact the transition to adulthood, researchers point to findings that children of immigrants, particularly Mexican, Laotian and Cambodian immigrants, are among the least likely to achieve any higher education (Rumbaut and Portes 2006). Again, the link between education and independence puts the fastest growing population at a distinct disadvantage. The inability to successfully transition to adulthood leaves families and subsequently communities at a continued disadvantage to support these struggling emerging adults (Furstenberg Jr., Kennedy, Mcloyd, Rumbaut and Settersten Jr. 2004).

\section{How do parents help or hinder independence?}

While both class and race clearly have an impact on the attainment of independence, one area that has had little examination is the effect that an emerging adult's relationship with parents or primary caregivers has on this transition. Parents and caregivers play a significant role in the life of a child as they serve initially as protectors and then provide children and adolescents with the skills and nurturing needed for survival. Theorists who examine the impact parents have on children discuss the two-fold relationship of helping children launch into the unknown and 
preventing or protecting them from unwanted harm. Attachment theory (Bowlby 1969) explains how parents provide a secure base from which children launch while control theory (Nye 1958, Hirschi 1969) shows how parents keep children from behavior that would prevent or inhibit their achievement of adulthood. Attachment explains the "push" in this relationship, while social control explains the "pull" mechanism in the parent-child relationship. The combination of these push and pull theories paint a robust picture of the parental role in emerging adult development and will serve as the theoretical framework for this study.

Does the relationship between a parent and child ultimately affect the ability to become independent in emerging adulthood? This question is at the crux of this study. If this relationship is found to be an important indicator of becoming independent, then more attention might be given to fostering this relationship throughout the life course. A successful society depends on functioning independent adults. It is important to know the barriers to becoming independent and then find ways that can maximize the development of a new generation of adults. This study aims to answer this critical question. 


\section{CHAPTER II}

\section{Review of Literature}

Why Do Parents Matter?

One of the inevitabilities in life is that individuals will age and their physical bodies will change. What is not a given is the magnitude of development that will occur along the way. Sociologist Kingsley Davis highlighted the fact that human development is a product of socialization when he studied a young five-year-old girl who had been hidden in a storage room for her short life, tied to a chair and unable to move (1940). In his observations of this tragic situation, he found that the emaciated child could not laugh, speak, or even smile. This extreme case highlights the fact that individuals need other individuals to develop into healthy people. Parents play a critical role in this development because they are the first caregivers of young children.

Theoretical Framework for the Parent-Child Relationship

While it is commonly understood that parents have a substantial effect on children, what remains uncertain are the ways by which a parent impacts a child's trajectory in their early adult years. Will children become self-sufficient adults regardless of parental relationship? The answer to this question lies within literature that theorizes and tests the affects of the interaction between a parent and child and the subsequent developmental outcomes for that child. As mentioned previously, two 
theories speak directly to the role of parents within the lives of their children:

attachment and social control. These two theories explore two forces, push and pull, that work together to help launch a child into adulthood.

Figure 2.1 The Push and Pull Factors: Attachment and Control Working Together

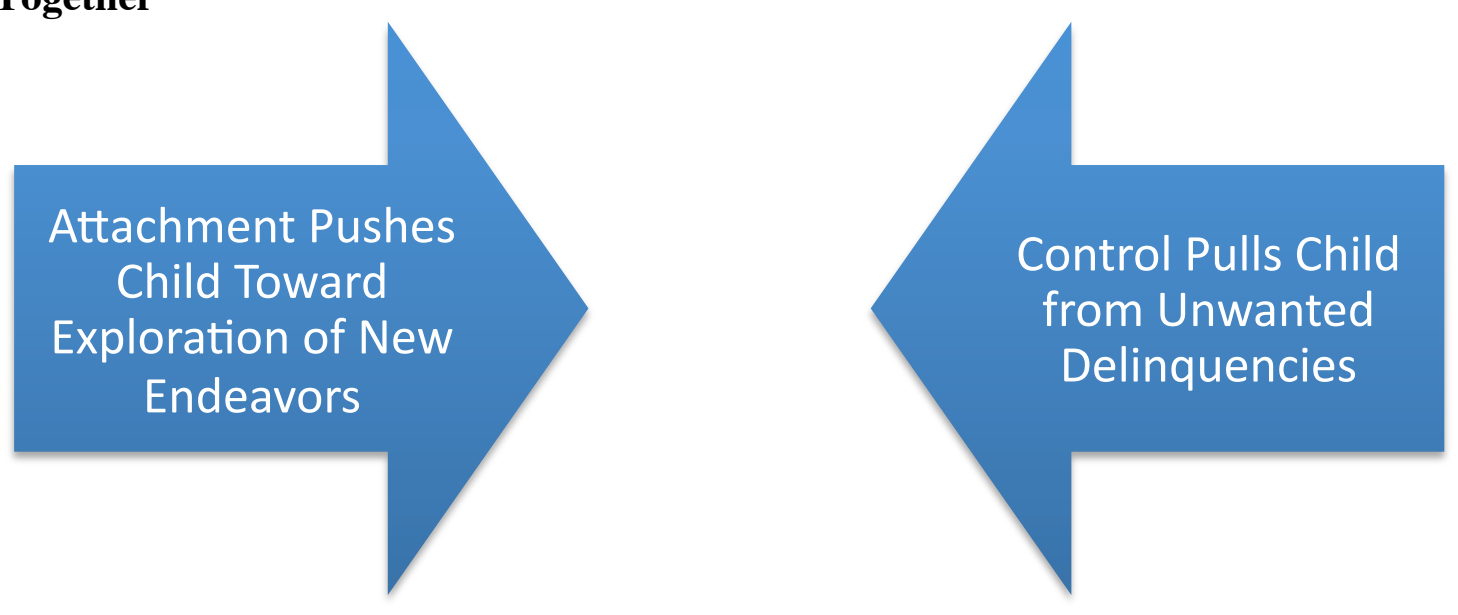

First is the psychological theory of parental attachment, which claims in essence that the "secure base" provided by a parent will facilitate the exploration of the child's environment and the prevention of debilitating psychological problems (Bowlby 1969). It is the security of the attached relationship that pushes a child toward new challenges, especially those found in the adulthood transition. Second is Travis Hirschi's (1969) theory of social control, which asserts that children with a highly attached relationship to parents will be less likely to commit delinquent behaviors that may in turn prevent a timely and successful progression into adulthood. This theory contributes the pull factor in the parent-child relationship that essentially prevents children from participating in delinquent behaviors, thus delaying the transition to adulthood. The following review of literature will explore these 
complementary theories, investigate the social variances within each theory, and then draw the connection between the theories and their implications for the successful transition to adulthood.

\section{Attachment as a Theoretical Framework}

The study of parental attachment as an explanatory model began with psychoanalyst John Bowlby and his three volumes titled, Attachment and Loss (1969, 1973, 1980). In his framework (1982), he asserts that attachment is a motivational system that evolved out of the protective function that comes from parental relationships. A child becomes attached to his/her caretaker and emits a cry, which then elicits a response from the caretaker. The type of caretaker response that is given interacts with the child's behavior to create one of four types of attachment: 1) secure,

2) anxious resistant (ambivalent), 3) anxious avoidant, or 4) disorganized. In a secure attachment pattern, the caretaker is sensitive to the infant's signals, which results in a sense of comfort experienced by the infant and confidence to explore his or her environment. The "anxious resistant" attached infant responds with either rejection of the caretaker's response or clings to the caretaker, who in turn is inconsistent in his or her actions toward the infant. The next form of attachment is the "anxious avoidant" child who ignores the caretaker's actions, in response to a parent who pays little attention to the child's signals. Finally, when there has been a history of abuse, psychosis or unresolved loss, the child will appear dazed or startled at the caretaker's actions, exhibiting the fourth category of attachment, "disorganized" (Kenny and Barton 2002). These four types of attachment represent the variety of relationship 
interactions that can be exhibited between a parent and child. But why does attachment matter? The next section will outline the results of various types of attachment.

\section{Outcomes of Variable Parental Attachment}

As researchers and clinicians have studied parental attachment over the years, they have discovered that parental attachment is indicative of a variety of positive outcomes well into adult life (Wintre and Yaffe 2000; Kenny 1987; Mattanah, Brand, Hancock 2004; Schultheiss and Blustein 1994, Bucx and van Wel 2008; Kenny and Rice 1995). One important outcome that has implications across the lifespan is the increased ability to tolerate anxiety-arousing situations and the fostering of environmental exploration (Ainsworth et al. 1978, Kobak \& Sceery 1988 in Kenny and Barton 2002). In the study conducted by Mary Ainsworth and her colleagues, individuals with a secure attached parent-child relationship were able to better withstand what they call the "strange situation." This means that when an infant is faced with a new environment or unfamiliar people, he or she is better able to tolerate the change and then explore his/her environment. In her later work, Ainsworth (1989) found that these infant attachment relationships carried over into adolescence. It is hypothesized that these patterns of attachment become "internalized over time to form internal working models of self, others and the physical environment" (Bowlby 1973). When infants have caretakers who are reliable and responsive, Ainsworth (1989) asserts that the infant develops an "internal working model" that is worthy of a consistent response and therefore is positive and secure. 
To understand the implications of a securely attached parent-child relationship, it is helpful to investigate the findings of previous studies. Children's behaviors manifest differently as they grow and develop, gaining more sophisticated responses and understandings of their own attachment. One such study has shown that the development of this secure base is helpful in dealing with the numerous biological, social and psychological changes that are abundant in adolescence (Kenny, Moilanen, Lomax, and Brabeck 1993). In this study it was determined that in the sample of eight-grade boys and girls, attachment to parents had a positive affect on psychological functioning, as subjects who displayed greater attachment had fewer depressive symptoms. More recently, Kenny and Sirin (2006) have replicated this study with a population of emerging adults, ages 22 to 28 , and again found that a close parental relationship had a positive impact on reports of depressive symptoms.

While this research project will not attempt to measure attachment using the psychological constructs found in much of the previous literature, its theoretical framework is based on the same notion that having a close or "securely attached" relationship with one's primary caregiver or parents will result in positive outcomes such as feeling secure enough to face a new situation. It is further held that this push or launching mechanism will in turn facilitate achievement of adulthood markers such as going to school, moving away from home, or finding that first job.

This study will contribute to the continuation of this research for individuals beyond adolescence, the emerging adults. One can imagine a scenario of a strange situation this age group might encounter such as a job interview or paying for one's 
living expenses. This study hypothesizes that individuals who have found a secure base in their parents will be more likely to adjust to these and other strange situations.

Much of the literature that adheres to the attachment model has investigated the parent-child relationship and its influence on adolescent outcomes. A few researchers have offered studies with emerging adults as the sample population (Soroku and Weissbrod 2005; Taub 1997; Kenny and Rice 1995; Kenny and Sirin 2006). While this literature has measured psychological wellness as a dependent variable, there are no known studies that test whether or not this relationship also aids in the achievement of adulthood. This study will contribute significantly to this gap in the literature as well as help researchers understand the continued affect that a parentchild relationship has throughout the life course.

\section{Social Control Theory}

While the psychological constructs of attachment are helpful in explaining the importance of the parent-child relationship, sociologists emphasize the social nature of this interaction. The language of a "secure base" that is found in the psychology literature becomes "social control" in sociology. Control theories assume that the greater bond an individual has to society, the less likely he or she is to commit delinquent acts and the more likely he or she will act normatively (Durkheim 1961; Hirschi 1969; Nye 1958/75). Indirect control by parents was described by Nye (1958/75) who found that as negative feelings toward parents decreased, social control increased. Hirschi (1969) describes the interconnected elements of bond in four ways: 
attachment, commitment, involvement, and belief. Briefly, attachment is the idea that strong social attachments to family, peers or school, for instance, encourage conformity while weak ones promote deviance. Commitment implies that an individual acts rationally and makes choices out of fear of consequences, thus exhibiting a commitment to conventional norms. The concept of involvement assumes that the more time a person spends doing conventional things, the less time they will have for deviant acts. And finally, Hirschi uses belief to describe an individual's adherence to a set of rules that he or she is socialized to believe as valid (1969).

Hirschi and later researchers have used social control theory to understand the likelihood of a person to commit a crime based on the individual's attachment to parental figures (1969, Magnino 2009, Rankin and Kern 1994, Cernkovich and Giordano 1987). Other studies indicate that youth who are more highly attached to their parents are also more likely to avoid early pregnancy and are less likely to engage in sexually risky behaviors (Fisher, Fisher, and Rye 1995; Gillmore et al. 2002; Luster and Small 1994). Research indicates that individuals who are more highly attached to one or more parents are less likely to report having committed delinquent behaviors such as drug use, truancy, theft or acting out violently (Rankin and Kern 1994).

Avoiding delinquent behaviors, crime resulting in incarceration, dropping out of school, or quitting sustainable employment, may be assumed to facilitate successful achievement of independence. Previous literature has examined each of these factors 
individually, but has failed to investigate the effect of parental attachment on becoming an independent adult. This study contributes to the emerging adulthood literature as it examines becoming independent from parents and the role a parentchild relationship has on this achievement.

\section{Connecting Two Theories: Attachment and Social Control}

Both attachment theory and social control theory provide a helpful framework for understanding how the parent-child relationship can affect various outcomes. Attachment stresses the ability of an individual to explore his or her environment and avoid debilitating psychological stresses when encountering a strange situation. This theory helps us understand the push or launching mechanism that theoretically is a product of a secure parent-child relationship. Even a child with more advanced cognitive reasoning capacities, such as an adolescent or emerging adult, might respond out of this attached relationship in the same way a child does. For example, an emerging adult who feels securely attached to his or her parent might feel secure in a strange situation such as living in one's own apartment. Attachment researchers have

yet to fully understand how far into human development the affects of attachment may reach. This research will contribute to this endeavor.

Social control theory adds to our understanding by explaining why the parentchild relationship deters emerging adults from entering into delinquent acts that prohibit individuals from becoming successful adults. This type of control can be seen as the pull or prohibitive force that keeps the child from delinquency such as dropping 
out of school, committing crimes, or quitting a full time job. Therefore, understanding the influence of a parent on the life of a child can been seen through a complementary push and pull forces as represented in Figure 2.1 above.

Becoming independent requires the emerging adult to confidently launch into strange and unknown situations while also avoiding circumstances that would delay or prohibit these same achievements. The current study uses the above model to explain how two theories of parent-child relationship attachment work together to both push and pull an individual towards independence.

\section{Social Forces Affecting the Parent-Child Relationship}

Once the theoretical foundation is clearly laid that this attached relationship matters, it is critical to understand the social variations of parent-child relationship. Social forces such as age, race, class, gender, and family structure affect the relationship a child has with his or her parent. Therefore these factors must be taken into consideration when creating a model that tests for the causation of the parentchild relationship alone. The following review of literature will capture what is currently understood about the parent-child relationship in relation to these various social background characteristics. It must be noted that in no case is this literature exhaustive. Kenny, for instance, reports in her anthology of parental attachment that literature examining the variation in parental attachment by race, gender and sexuality "remains limited" (In Demick and Andreoletti 2003). This study aims to contribute to the limitations currently expressed by leading researchers. 


\section{Race and Parent-Child Relationship}

Two studies indicate that Black adolescents reported higher levels of intimacy with their parents than did their White peers (Cernkovich and Giordano 1987;

Giordano, Cernkovich and DeMaris 1993). In their study of adolescents ages 12 to 19, Giordano and her colleagues found that Black students scored significantly higher on items measuring the level of intimacy with parents (1993). In addition, Hinderlie and Kenny (1999) looked at the college adjustment of Black students and found a positive association between adjustment and parental attachment. These studies give support to the argument that race matters when considering parent-child relationships.

While these studies focus specifically on Black late adolescents, studies regarding the connections between parents and children of other races are clearly missing from the attachment literature. Central to the study of the experiences of racial minorities is the work of Portes and Rumbaut (2001). Their work, which focuses on the experiences of 5,262 second-generation immigrants, investigates the measures of parent-child conflict and family cohesion. They found that Latino youth have the most cohesive families as well as the lowest levels of parent-child conflict. Comparatively, Asian youth report lower levels of family cohesion and higher levels of parent-child conflict, particularly among Hmong and Cambodian respondents. The work of Portes and Rumbaut supports the notion that the nature of the parent-child relationship differs by ethnicity. It is not clear, however, what the exact differences may be. This study will look specifically at the variations found in multiple racial categories. 


\section{Social Class and Parent-Child Relationship}

Social class influences many interactions between parents and children. Lareau (2003) discusses the concept of "concerted cultivation" to describe the type of middleclass child-rearing that transmits important life skills such as language use, reasoning and personal advocacy within institutions. These attributes provide capital that emerging adults will eventually use to negotiate the institutions of education and work life found within the social norms which reflect those of the middle-class family. Working-class and poor children are at a distinct disadvantage as their parents interact with a style that fosters the "accomplishment of natural growth" (Lareau 2003), which is not ultimately valued in adult institutions such as higher education and the work place. For example, if two individuals were denied a job, the child raised under the concerted cultivation model might contact the employer to petition the denial, while the child raised under the natural growth model would be more inclined to accept the rejection as final.

While this study explains one way in which the parent-child relationship could affect the transition to adulthood, the question remains as to whether there are classbased distinctions in the closeness of parent-child relationships. In her 2005 study, Bogard indicates that the U.S. Department of Health and Human Services states that "youths of ages 12-17 years in the United States whose families make over $\$ 100,000$ a year report feeling very close to their parents less than do all other teens from various socioeconomic backgrounds." This finding would suggest that emerging adults who come from lower income families would be more likely to exhibit a close relationship 
with one or both of their parents. This study will examine this bivariate relationship and use this factor as a control for the net effect of parental attachment on adulthood transitions.

\section{Gender and Parent-Child Relationship}

While both race and class indicate variability in the parent-child relationship, gender appears to have the most salient affect of these three factors. An examination of literature regarding the gendered nature of the parent-child relationship reveals that mothers and daughters experience a closer bond than do mothers and sons (Thorton et al 1995). Among college students, women are more likely to have a close relationship with both parents, indicated by calling home more frequently and the sharing of deeply personal issues (Sorokuo and Weissbrod 2005).

In addition to examining the gender of the child, literature indicates that there is variability in perceived attachment according to the gender of the parent. Some studies indicate that youth are more highly attached to their mothers than they are to their fathers (Silverstein, Bengtson and Lawton 1997; Rice, Cunningham, \& Young 1997). It is clear that gender plays a role in the parent-child relationship and therefore must be examined as a control variable in this study's models. 


\section{Family Structure}

The evidence in previous literature is not conclusive regarding the effect a divorce has on the attachment of a child to their parents. Bucx and van Wel (2008) state that in their sample of 1,064 young adult respondents, there is a negative association between parental divorce and attachment. On the contrary, in a study of the divorced families of 200 young adult children, Carranza Kilmann and Vandemia (2009) concluded that the personality style of the parent was an indicator of attachment felt by the child, but not the divorce itself. This study will look at the attachment levels for children of both stable and divorced.

\section{Age in the Life Course}

The final possible predictor of attachment considers the notion that the developmental stage of the child within the life course. Blos (1979) argues that attachment lessens as a child becomes more independent, which hinges on the individuation and separation theory. Stryker (1968) argues to the contrary, stating that as children achieve the same adult roles as their parents, they express greater sentiments of attachment and understanding. Contributing to this notion, Buck and van Wel (2008) find that the more markers of adulthood that individuals have achieved, the closer they will feel to their parents. The project at hand will test this to determine if the same phenomena holds true for the sample under investigation. 


\section{Figure 2.2 Social Forces and Parent-Child Relational Variability}

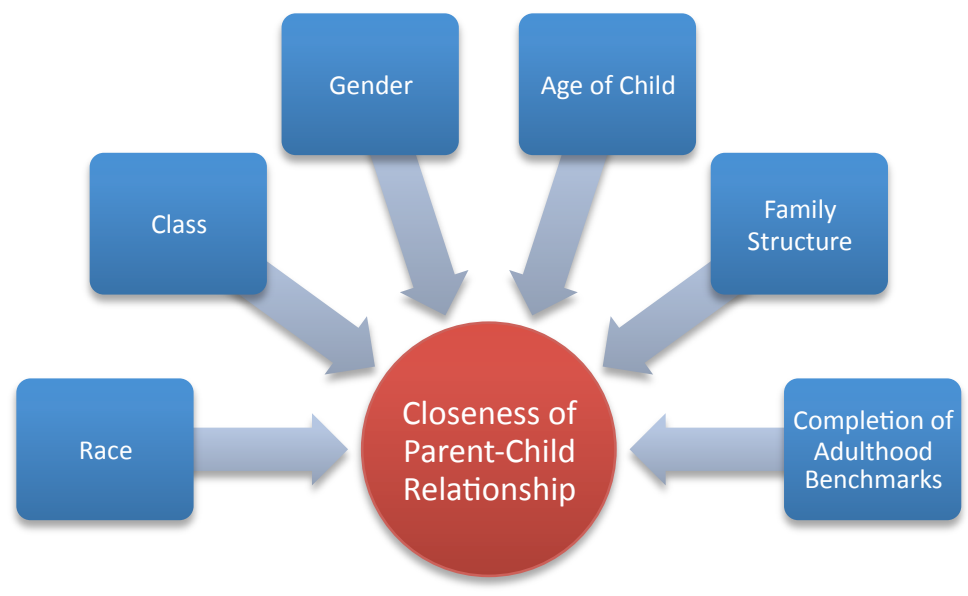

The interaction between various social forces and the closeness of the parentchild relationship is depicted in Figure 2.2 above. As described in the above review of literature, each of these variables could have an impact on how close or attached a child feels to his or her parent.

\section{BECOMING INDEPENDENT IN THE TRANSITION TO ADULTHOOD}

The crux of this study is to determine whether or not a positive parent-child relationship increases the probability of becoming an independent adult. The following pages will review what is known about this period of life called emerging adulthood and describe the variations in becoming an independent adult.

First, that background of this stage in the life course must be established. How does a young adult know when they have completed their transition out of adolescence and successfully arrived at adulthood? Adulthood is a complicated concept that has different meanings to different individuals, as this review of literature will show. 
The period of life between ages 18 and 25 has been termed "emerging adulthood" by Jeffery J. Arnett (2004). Arnett is a psychologist who conducted years of research using interviews, focus groups, and surveys to better understand what was happening during this period of life. He outlined five distinctive characteristics of individuals during this period. First, it is a time of identity exploration in realms such as love, work, and beliefs. Emerging adults typically experiment with several sexual partners, try out different majors in college, and may skip around from one short-term job to another. Second, there is prolific instability in emerging adults as they leave home and often return. Arnett explains that in the 1920's only about $20 \%$ of individuals returned home after leaving, compared with today where just over half return home (2004). Third, individuals are often self focused as they attempt to chart their course for the remainder of their lives. Their primary interests lie in establishing their educational trajectory and finding the "right" job or job-track. Fourth, emerging adults also feel in-between, not a teen but not quite an adult. Many want the freedom to create their own daily schedules, but still covet the financially security that comes from parents or caregivers. Finally, emerging adults have a sense that their futures are full of possibilities and open to a variety of courses.

In addition to describing the nature of this period of life, Arnett asked his subjects to identify how they know they have reached adulthood. His qualitative research found that the following three main features of being an adult can more concretely mark arrival into full adulthood: accepting responsibility for yourself, making independent decisions, and becoming financially independent (Arnett 2004). 
The first and second markers, accepting responsibility for oneself and making independent decisions, indicated that individuals made choices in sex, work, and education, and then reaped the rewards or paid the consequences for those decisions. His respondents also felt that adults would cease asking parents and family for money or expecting them to provide food and shelter. The essential concept in becoming adult according to Arnett's studies is independence from parents.

While Arnett's study focuses on three essential psychological and developmental tasks, other researchers have commonly used various concrete measures of adulthood, such as getting married/partnering, leaving home, having children, starting work, and finishing school (Settersten et al. 2005). In an effort to further examine when individuals "feel like an adult," Shanahan and his colleagues (2005) have determined that cohabiting or marriage, having at least one child, and owning a home or renting an apartment to be clear markers. In their study one thousand ninth graders were surveyed annually for 11 years. They asked under what circumstances those respondents "felt like an adult." Shanahan and his colleagues explain that people "feel like an adult" under different conditions, such as when they are with romantic partners as opposed to when they are with their parents. Individuals were also most likely to feel like an adult when they were financially independent, became married or cohabiting, and became a parent (Shanahan et al. 2005). Again, the common thread in these studies is independence.

In a third major study that explains how people conceptualize adulthood, Furstenberg and his colleagues report that most individuals understand adulthood as 
(1) the completion of one's education, (2) becoming financially independent and (3) working full-time (2004). Their information was gathered from a series of questions that were added to the General Social Survey in 2002. In the same data, only about half of the respondents felt that getting married and having a child were markers of achieving adulthood status, implying that these markers merely represent lifestyle choices.

Each of these researchers has contributed to the understanding of what it means to move from one developmental stage to the next: adolescence to emerging adulthood to full adulthood. While education, partnering and becoming a parent are in fact common occurrences in adulthood, they each represent individual lifestyle choices that many adults do not choose and therefore are flawed measures of adulthood. Therefore, this study will use the pervasive idea, consistent within all of the above research, that a clear indicator of adulthood is independence. The following pages will show the variation in and give definition to independence.

\section{Leaving the Nest as Independence}

In the United States, the cultural trend as children age is to leave their parents' home and establish themselves in autonomous households. The psychological constructs of adulthood mentioned by Arnett (2004), independent decision making and being responsible for oneself, confirm that living independently from one's natal household signifies a significant step in achieving adulthood. 
The transition from living with parents to living on one's own is not as straightforward as it may have been in previous generations. Historically, when a child reached age 18 , he or she went to college if from a middle class family, or got a full time job and subsequently moved out on their own. However, as indicated above, studies show that emerging adults are living with their parents in greater numbers than ever before (Fussell and Furstenberg 2004). In their study of the labor market experiences of emerging adults, Hill and Hozer (2007) cite that in 1985, 45\% of the young adults ages twenty to twenty-two in their sample lived with parents, while in 2003 that figure jumped to $57 \%$. This indicates that more emerging adults are choosing to live with parents than in recent decades. Rumbaut (2006) points out that in the 2000 census roughly one third of individuals ages 18 to 34 still lived with their parents or in the home of their youth.

What factors contribute to a person's likelihood of leaving the nest? In their data, Hill and Hozer (2007) determined that individuals who were most likely to live at home in 2002 were individuals without a college degree orenrolled in a four-year college. Hispanic males, Black females and, according to their study, those from higher income families are more likely to live at home than those from lower income levels. This means that, according to this study, independent individuals are most likely enrolled in a four-year college or university, have a bachelor's degree, are nonHispanic females, non-Black males or come from lower income families.

In contrast to the study by Hill and Hozer (2007), Rumbaut's study (2004) indicates that with respect to sex, $52 \%$ of males and $59 \%$ of females ages 18 to 24 had 
moved out of their parents' home. As the age range increases, $81.9 \%$ of males and $86.4 \%$ of females ages 25 to 29 had left home. These figures show that despite the age of this individual, females are more likely to leave the nest than are males.

Another pivotal study investigates the nest-leaving practices of 18 to 30 year olds, using U.S. Census data from 1970 and 2000 (Yelowitz 2007). This study confirms earlier notions that independent living varies by demographic characteristic and over time. This study shows that the older a person is, the more likely he or she is to live independently. Also, individuals who live in areas with higher housing costs are more likely to remain living with their parents. Yelowitz concludes that over the last 30 years, individuals have become less likely to live independently.

In light of the aforementioned research, the present study will investigate whether or not parental attachment is related to living independently while controlling for the salient characteristics that predict nest leaving: age, race/ethnicity, gender, family SES, bachelor's degree achievement status, and educational status. These variables have demonstrated predictive value in leaving one's natal home.

\section{Variability On the Path to Adulthood}

In addition to understanding independence as described above, it is helpful to see how and in what ways various populations achieve independence. The following pages will give detail to the varied adulthood trajectories that are experienced by emerging adults. 
There are three key studies that examine the different ways that emerging adults reach their destination. Mouw (2005) uses life-history data from the National Longitudinal Survey of Youth (NLSY79), which annually surveyed over twelve thousand individuals from 1979 to 1998 . Using the five basic markers of adulthood, Mouw found that the order in which individuals achieve all five markers has no significant effect on income at age thirty-five. However, the timing of events such as first marriage and when work started had a significant effect on income attainment.

Another study that examined variability in the transition to adulthood indicated that men and women had significantly different paths (Sandefur, Eggerline-Boeck, Park 2005). These researchers used two datasets, High School and Beyond (HSB) and the National Educational Longitudinal Study (NELS), to look at who was more likely to avoid behaviors that delay independence, such as dropping out of school or having a child early in life. They discovered that men were most likely to fall into one of four classes related to education attainment and family formation in the following order.

(1) Limited postsecondary education and married with children

(2) Limited postsecondary education and no family

(3) BA or higher and married with children

(4) BA or higher and no family.

Women however landed in the following sequential classes.

(1) Limited postsecondary education and married with children

(2) BA or higher and no family

(3) BA or higher and married with children

(4) Limited postsecondary education and child/children

This study is useful because it depicts that men are more likely to postpone marriage and women are slightly more likely to attain a Bachelor's degree. Both of these 
factors, the authors indicate, lead to greater economic success and eventual independence.

The third study of interest explores the varied paths to adulthood (Osgood, Ruth, Eccles, Jacobs and Barber 2005). This study sampled youth from Michigan in $1999(n=1,410)$. Using latent class analysis, the researchers determined the probability that individuals would follow certain paths to adulthood. Dividing their study into typologies, "educated singles," or individuals with a Bachelor's degree who were not married, constitute the largest group within their sample. The next largest group was "educated partners," or those who have a degree and are married. Their findings support the assertion that emerging adulthood is a diverse and elongated process (Arnett 2004).

In summary, the above review of the literature shows that becoming independent hinges on various social predictors. Specifically, the literature indicates that being older, female, White, not enrolled in a four-year college or university, or having a Bachelor's degree all have positive predictive value in attaining independence (Hill and Hozer 2007; Portes and Rumbaut 2001; Rumbaut 2004; Goldscheider, Thornton and Young-DeMarco 1993.) This study will build on previous research and examine a further possible predictor of becoming independent that is a strong parent-child relationship. 


\section{CONNECTING PARENT-CHILD RELATIONSHIP AND INDEPENDENCE}

This review of literature has explained that parents affect the development and potential life transitions of their children. Attachment theory and control theory help articulate both the push and pull forces that parents exert on their children.

Next, the literature review detailed the understanding of independence and the variations within social variations. This study takes the theoretical framework of attachment and control and applies them to becoming independent. In Figure 2.3 below, a conceptual model for this study shows how the parent-child relationship influences independence. In essence, this study hypothesizes that the greater attachment children have to their parent(s), the more likely these children are to become independent.

\section{Figure 2.3 Conceptual Model for Predicting Independence}
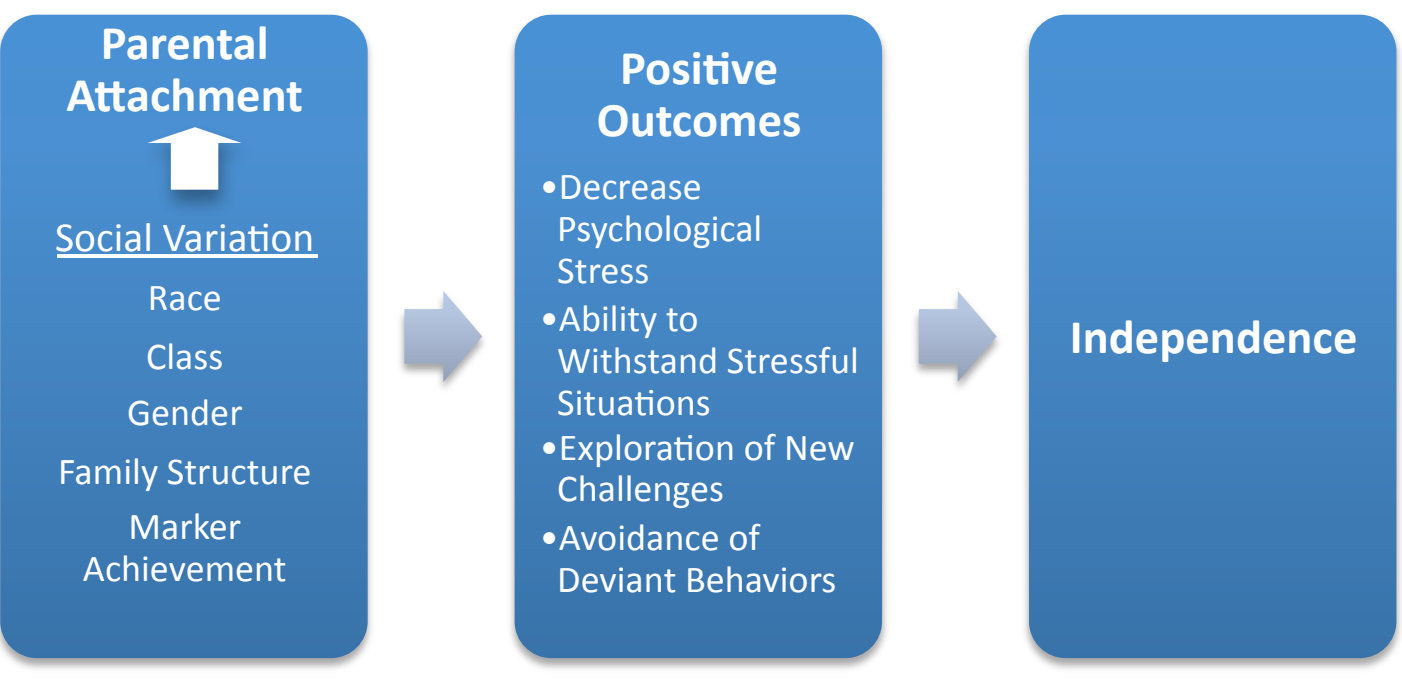


\section{Hypotheses}

The following hypotheses are derived from the previously cited literature regarding becoming independent and from the theoretical framework that parental attachment affects a child's trajectory.

Hypothesis 1: High parental attachment in youth will have a positive influence on being independent in emerging adulthood.

Hypothesis 2: Being older will have a positive affect on independence.

Hypothesis 3: Females are more likely to be independent than males.

Hypothesis 4: Individuals from families with lower SES will be more likely to be independent than those of higher SES.

Hypothesis 5: Being White will have a positive affect on independence.

Hypothesis 6: Not being currently enrolled in a four-year college will have a positive affect on being independent.

Hypothesis 6: Having a Bachelor's degree will have a positive affect on being independent. 


\section{CHAPTER III}

\section{METHODOLOGY}

\section{DATA}

This study tests the hypothesis that parental attachment has a positive influence on becoming independent in emerging adults. In order to do this, a secondary analysis of the public-use data from the National Longitudinal Study of Adolescent Health (Add Health) Wave III is conducted. The strength of conducting a secondary data analysis of a large representative national database over other forms of social inquiry is that one is able to observe broad patterns in social behaviors within an extensive number of cases that just would not be feasible using individual interviews or focus groups.

Why Add Health? These data represent a longitudinal study of youth in three waves, conducted from the time the respondents were ages 13 to 17 (1994-1995) through the third wave (2001-2002), at which time these respondents were ages 18 to 28. The sampling frame for Add Health was a database of 80 high schools that were selected to represent all U.S. schools with respect to region of the country, urbanicity, size, type, and ethnicity. Oversamples were drawn for the final data that included ethnicity, saturation, disabled status, and genetics. Germane to the current study is that oversampling for race and ethnicity included Blacks from well-educated families (a parent with a college degree), Chinese, Cubans and Puerto Ricans. 
In addition to the in-school questionnaire, parents or guardians of the respondents completed an in-home questionnaire for Wave I and an in-home interview for Wave II. Finally, in Wave III, in-home interviews were conducted, questionnaires were given and education data was collected. In this wave of data collection, partners were also interviewed and saliva and urine specimens were collected. In comparison to other datasets that attempt to capture youth behavior, Add Health is superior due to its broad sampling.

The second strength of using Add Health in this study is found in the scope of its variables. In the first wave of data, which was used to fill in some of the missing information in this study, there are over 2000 variables, when considered as a whole, depict in part the lives of these youth. The Wave III data contains an equally broad scope of variables. However most important to this study is that this dataset includes questions regarding the child's relationship with their parents. Because this variable is of key theoretical interest, it was important to find data that both had respondents in the emerging adulthood age range and contained information about the nature of the relationship between parent and child.

\section{VARIABLE DESCRIPTIONS}

Dependent Variable. The objective of this study is to focus on independence as it is affected by parental attachment. The dependent variable, independence, is conceptualized by residential status. Independence is defined as living in one's own dwelling, not with parents or in group-quarters. All known previous research in this 
area has focused on independence as comprising several different measurements such as residential independence, working full time or making a wage that is above the poverty level (Yelowitz 2007; Goldsheider et al 1993; Danziger and Rouse 2007; Hill and Hozer 2007).

Previous research has operationalized residential independence as living on one's own or in group-quarters (dormitories and military barracks; Goldscheider, Thornton, Young-DeMarco 1993). However, considering that the previously mentioned study found that college students and those in the military often return home before making a final departure, the present study will not include group quarters living as independence.

This study operationalizes independence as physically living apart from family (see Appendix A for full description of questions.) The independent respondents identified that they lived in "their own place" and not in another person's place or group quarters, which is consistent with indicators used in previous research (Danziger and Rouse 2007, Hill and Hozer 2007, Yelowitz 2007). One half of the sample was identified as independent.

Parental Attachment. The key concept of theoretical interest is the effect of parental attachment on independence. While research in psychology uses a very formal and in-depth instrument to operationalize parental attachment (The Parental Attachment Questionnaire, Kenny and Sirin 2006), this study will follow sociological research that looks at measures of self-described feelings of closeness or attachment to 
one's parental figures (Haynie 2001, Mangino 2009). In order to account for a time ordered sequence, Wave 1 data, collected in adolescence, is used to determine parental attachment as a predictor of independence in emerging adulthood. Parental attachment is computed using the mean of two questions for the respondent's mother and father: "How close do you feel to your mother/father?" and "How much do you think your mother/father cares for you?" These two questions consistently have significantly strong correlations for each parental figure (Pearson's $r_{2}=+.574$ to +.7 , $\mathrm{p}<.01)$.

Respondents had five response options on a Likert-scale ranging from "not close at all" to "extremely close." Parental attachment is the mean across the four questions for both parental figures. In this study, all results were rounded to the nearest whole number to account for the low number of cases that fell between the integer ranges. The result was a five-category ordinal variable ranging from "very low attachment" to "high attachment."

A second parental attachment variable was also constructed from Wave 3 data to determine whether or not attachment changed over time. This data asked similar questions about previous residential parents. Again, the same two items were selected for both the previous residential mother and father. There was a net change of -.24 in parental attachment in Wave 3 when compared to Wave 1. This indicates that parental attachment decreased slightly over time, but still continues to remain high in emerging adults. 
Preliminary analysis of Wave I attachment indicates that it is highly skewed: $88 \%$ of the respondents scored a 4 or 5 with a mean of 4.43 and a standard deviation of 0.5 . This indicates the most children feel very close to their parents. Following the work previous researchers (Haynie 2001, Magnino 2009), parental attachment was converted into a dummy variable, which indicated whether or not the respondents were "highly attached" to their parents or not. This categorical variable was recoded to a binary variable where scores of 4 or higher signified that the respondent was "highly attached" (79.5\% of the sample), while scores of less than 4 indicated "low" attachment (20.5\% of the sample).

Control Variables. The final models include several controls for demographic and family characteristics that prior research suggests are associated with emerging adult independence. The following is a description of the construction of these variables. Missing values for each variable were coded as missing in final regression models and therefore not included in the final analysis.

Age. The emerging adults in this study ranged in age from 18 to 27 . Age was previously calculated by the original researchers using the date of birth given in Wave I of the study. The average age of the individuals in this sample was 21.84 .

Gender. In the public use data, a variable for biological sex is given with two response categories, one male and the other female. This was coded to a dummy variable with males $=0$ and females $=1$. About $54 \%$ of the respondents identified as female. 
Race. In the in-home survey, respondents were able to select their racial identity from among many categories and subcategories. The original data were then coded into general categories including Hispanic, Black, Asian, Native American/Pacific Islander, White, and other.

Research by Hill and Hozer (2007) indicated that Black females and Hispanic males were most likely to not live independently from their parents. They also indicate that Whites are most likely to live independently from their parents. Therefore, White is used as the reference variable with all other races excluded in the final models (White, not Hispanic=1, Not White=0).

Family SES. Parental education was used as the proxy for family SES because of the strong association between education and socioeconomic status (Bearman and Moody 2004; Haynie et al. 2004, Magnino 2009). Consistent with previous research, in a family with two parents, the highest level of education between the two parents was used. This variable was ordinal in nature and included the ten levels listed as follows.

1. Never went to school

2. Eighth grade or less

3. Greater than eighth grade/didn't graduate high school

4. Business/trade/vocational school instead of high school

5. Completed GED

6. High school graduate

7. Business/trade/vocational school after high school

8. College/didn't graduate

9. Graduated from college or university

10. Professional training beyond four-year college or university 
This variable construction is consistent with previous research that uses parental education as a proxy for SES (Magnino 2009, Bearman and Moody 2004, Haynie 2001). The average family SES was 7.06.

Family Structure. This variable refers to individuals who are from families in which parents are divorced or separated compared with stable two-parent families. It is constructed using information from the Wave 3 in-home questionnaire that asked first if the respondent's parents with whom he or she lived in adolescence (previous residential mom and dad) were still living together in the same household. Individuals who had parents who were no longer living together were coded "0" while the rest were coded " 1 ," indicating that the parents of their adolescence were still together. Eleven percent of the population comes from presumably separated divorced families.

In School. As previously noted, individuals who are currently enrolled in a 4year college or university are less likely to be independent (Hill and Hozer 2007). To control for this, a variable called "In_School" was constructed from two items that asked whether or not the respondent was currently in school and in what type of school he or she was enrolled. Individuals who were currently enrolled in a four-year college or university were identified as "in school" $(1=$ not in school, $0=$ currently in school). Two-thirds of the sample indicated that they were not enrolled in a four-year institution.

Completed Bachelor's Degree. This variable was a dummy variable constructed from an item, which asked respondents whether or not they had completed either a BA or a BS degree $(1=y e s, 0=n o)$. Only $11.5 \%$ of the sample had already 
earned a bachelor's degree. Descriptive statistics for all of the variables discussed above are shown in Table 3.1 below.

Table 3.1 Descriptive Statistics for All Variables

\begin{tabular}{|c|c|c|c|c|c|c|}
\hline Variable & Mean & Range & $\%$ of $\mathrm{N}$ & $\mathrm{N}$ & \# Missing & \% Missing \\
\hline Age & 21.82 & $18-27$ & & 4882 & 0 & 00.0 \\
\hline Sex & - & $0-1$ & & 4882 & 0 & 00.0 \\
\hline Male & & & 46.1 & & & \\
\hline Female & & & 53.9 & & & \\
\hline Race & - & & & 4876 & 6 & 00.12 \\
\hline White & & & 58.9 & 2870 & & \\
\hline Hispanic & & & 09.9 & 482 & & \\
\hline Black & & & 24.9 & 1213 & & \\
\hline Asian & & & 04.2 & 203 & & \\
\hline Nat. Am/Pac.Is. & & & 02.2 & 108 & & \\
\hline Family SES & 07.10 & $0-10$ & - & 4794 & 19 & 00.40 \\
\hline Family Structure & - & $0-1$ & & 3230 & 1652 & 33.80 \\
\hline Divorce & & & 11.4 & 367 & & \\
\hline Stable & & & 88.6 & 2863 & & \\
\hline Parental & 04.07 & $0-5$ & & 6370 & 134 & 02.06 \\
\hline Attachment & & & 00.2 & 11 & & \\
\hline Very Low & & & 02.8 & 134 & & \\
\hline Low & & & 17.5 & 845 & & \\
\hline Moderate & & & 49.1 & 2370 & & \\
\hline $\begin{array}{l}\text { High } \\
\text { Verv Hioh }\end{array}$ & & & 30.3 & 1463 & & \\
\hline Parental Attachment & 0079 & $0-1$ & & 6370 & 134 & 02.06 \\
\hline Low Attachment & & & 20.5 & 990 & & \\
\hline High Attachment & & & 79.5 & 3834 & & \\
\hline Independence & 00.50 & $0-1$ & & 4881 & 1 & 00.00 \\
\hline Not Independent & & & 50.3 & 2458 & & \\
\hline Independent & & & 49.7 & 2423 & & \\
\hline Enrollment & 00.83 & $0-1$ & & 6504 & 0 & 00.00 \\
\hline Not Enrolled & & & 16.8 & 1094 & & \\
\hline Enrolled & & & 83.2 & 5410 & & \\
\hline
\end{tabular}

SOURCE: The National Longitudinal Study of Adolescent Health, Wave III 


\section{ANALYTICAL APPROACH}

First parental attachment is examined as a dependent variable. Then parental attachment is examined as a dependent variable to independence. Independence variation is explored followed by a multivariate analyses to evaluate the hypothesis that parental relationship positively affects independence. Using logistic regression techniques, seven models were constructed and analyzed. Model 1 is the baseline model that examines the effect of Wave 1 parental attachment on independence in Wave 3. Each successive model added an independent variable in order to determine which variables contribute to independence, as depicted in Table 3.2 below.

Comparing the Naglekerke R-square statistic in each model shows the difference in the model strength compared to the first model.

Table 3.2 Logistic Regression Models

\begin{tabular}{clll}
\hline Dependent & \multicolumn{1}{c}{ Model 1 } & \multicolumn{1}{c}{ Model 2 } & \multicolumn{1}{c}{ Model 3 } \\
Variable & & & \\
\hline Independence & W1 Parental & W1 Parental & W1 Parental \\
& Attachment & Attachment & Attachment \\
& & Age & Age \\
& & Female \\
\hline
\end{tabular}

\begin{tabular}{llll}
\hline \multicolumn{1}{c}{ Model 4 } & \multicolumn{1}{c}{ Model 5 } & \multicolumn{1}{c}{ Model 6 } & \multicolumn{1}{c}{ Model 7 } \\
\hline W1 Parental & Wl Parental & W1 Parental & W1 Parental \\
Attachment & Attachment & Attachment & Attachment \\
Age & Age & Age & Age \\
Female & Female & Female & Female \\
White & White & White & White \\
& Family SES & Family SES & Family SES \\
& & Not in School & Not in School \\
& & Completed BA/BS \\
\hline
\end{tabular}




\section{CHAPTER IV}

\section{FINDINGS}

The guiding hypothesis for this study is that a strong parent-child relationship in adolescence has a positive influence on living independently from parents in emerging adulthood. The following pages will first explore parental attachment and then the variability in independence. The final section will look at the predictors of independence within this emerging adult sample.

\section{Parental Attachment}

Among the Add Health respondents, both adolescents and emerging adults show a strong parental attachment. Figure 4.1 below depicts the differences in attachment levels between Wave 1 adolescents, ages 12 to 18 , and their responses as emerging adults, ages 18 to 27 , in Wave 3 .

\section{Figure 4.1. Comparative Parental Attachment Percentages}

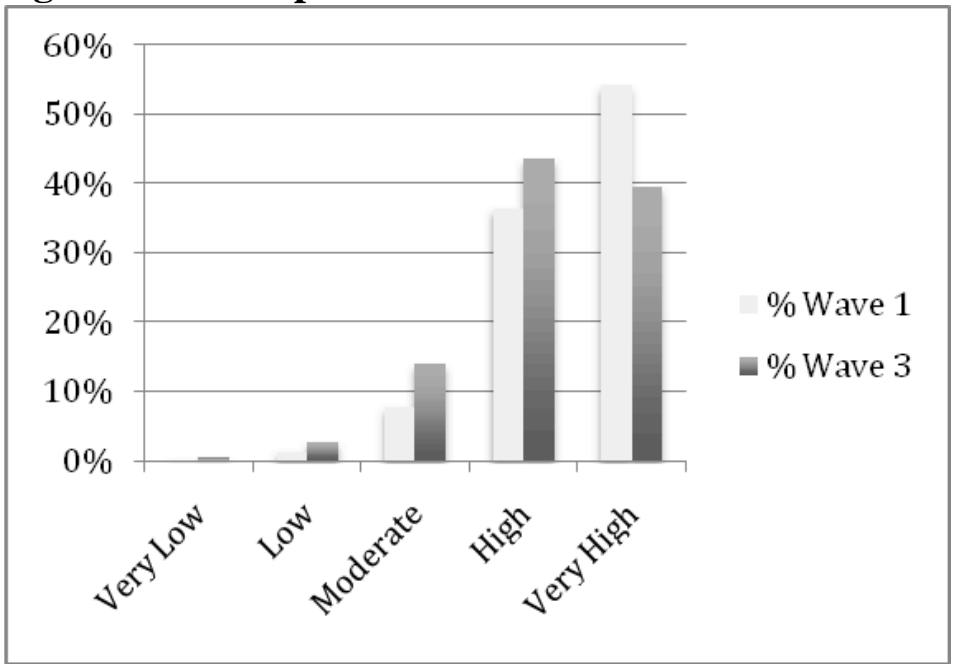

Source: The National Longitudinal Study of Adolescent Health, Wave 1 and 3 Wave $1 \mathrm{~N}=6370$, Wave $3 \mathrm{~N}=4675$ 
Both measures of attachment are negatively skewed in their distribution, with Wave 1 responses showing 90.7\% "high" or "very high" attachment levels and Wave 3 responses with $82.9 \%$ "high" or "very high" attachment levels. This indicates that while respondents expressed highly attached relationships with their parental figures in both adolescence and emerging adulthood, there is a slight decrease in average attachment as the respondents aged.

The remaining analysis will use parental attachment as recorded in Wave 1, unless otherwise indicated. Researchers have indicated that women are more likely to express attachment to their parents (Thornton et al. 1995; Sorokuo and Weissbrod 2005), males in the current study expressed a statistically significant higher degree of parental attachment $(\mathrm{p}=.001, \mathrm{~N}=4801)$. When measuring the strength of this relationship it was found that gender explains $6 \%$ of the variation in parental attachment (Cramer's V=.06).

With respect to age, there was little variation and no statistical differences among the means for either Wave 1 attachment or Wave 3 attachment. This came as no surprise since there was no known literature to support the notion that age should make a difference in parental attachment. However, one study does indicate that parental attachment often increases with the achievement of adulthood markers (Bucx and van Wel 2008). To test this hypothesis, cross-tabulations were conducted between parental attachment and the number of adulthood markers each individual had achieved: completing High School diploma/earning GED, working full time, living independently, partnering and becoming a parent. There was no statistical difference 
between individuals who had achieved more of the adulthood markers than those who had achieved fewer for either measure of attachment.

Next, the effects of race and family SES on level of attachment were considered. According to the literature, Asians are less likely to express sentiments of attachment toward their parents (Kenney 2006). When this hypothesis was tested, Asians had the lowest percentage of responses in the high attachment category. While it was not statistically significant, it may contribute to the Kenney's (2006) assertion that Asians are less apt to express extreme emotional connectedness. This claim, however, merits further investigation.

In regards to family SES, the literature indicates that individuals from higherincome families show lower parental attachment (Bogard 2001). Initial observation of the interaction between family SES and the two measures of parental attachment did not show any patterns or statistically significant differences $(\mathrm{N}=4881)$. This was in part due, however, to the low numbers of cases found in many of the cells. To account for these low numbers of cases, both variables were collapsed into general categories using high and low attachment for the parental attachment variable (Haynie 2009) and five categories for family SES: No GED/High School diploma, GED/High School diploma, some education beyond HS but no bachelor's degree, earned bachelor's degree and professional training beyond the bachelor's degree.

While parental attachment at Wave 3 showed no statistical significance, Wave 1 attachment showed a weak positive correlation ( $\mathrm{p}<.05$, Cramer's V=.048). Figure 
4.2 below depicts the comparison of attachment as recorded at Wave 1 with Wave 3 . This reveals that there is no association between Wave 3 measures of attachment and family SES. Wave 1 measures of attachment show that attachment increases slightly as family SES increases. This is in direct opposition to the aforementioned literature (Bogard 2001) that states higher SES families typically have lower levels of attachment.

\section{Figure 4.2. Parental Attachment, by Family Education}

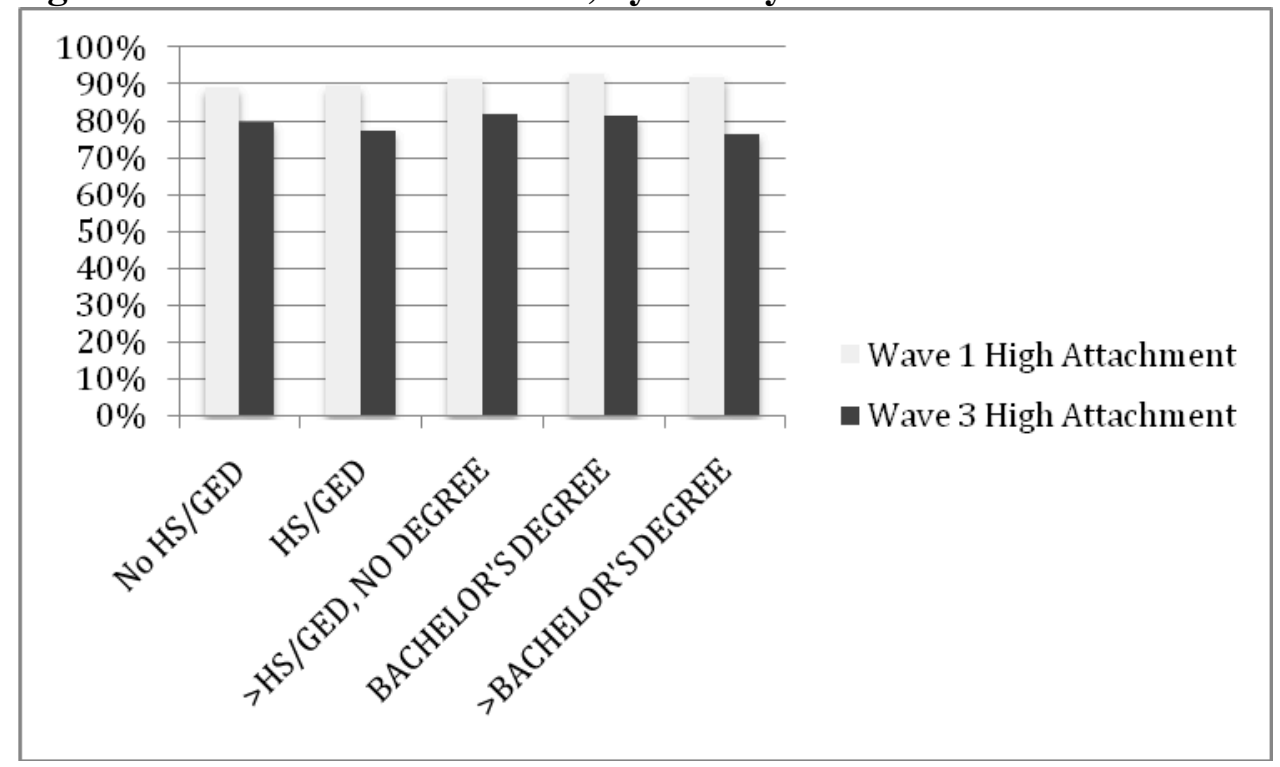

Source: The National Longitudinal Study of Adolescent Health, Wave 1 and 3 Wave $1 \mathrm{~N}=4714$, Wave $3 \mathrm{~N}=4739, \mathrm{p}<.05$, Cramer's V=.048

Family structure was the next social background characteristic to be considered. The bivariate analysis confirms with statistical significance the literature stating that people from divorced families express lower levels of attachment as measured at Wave 3 (Bucx and van Wel 2008, $\mathrm{p}=<.01, \mathrm{~N}=3220$ ), while attachment measured at Wave 1 showed no statistical significant difference. For Wave 3, 84.1\% 
of individuals from stable homes were highly attached while only $71.3 \%$ of individuals from divorced homes expressed high parental attachment.

Each of the independent variables was examined in a correlation matrix to determine whether or not multicollinearity was present. The results indicate that there was no evidence of multicollinearity. Table 4.1 on the following page presents summary statistics on the variation in parental attachment for the background variables that previous studies have found to influence attachment. 
Table 4.1. High Parental Attachment at Wave 1

\begin{tabular}{|c|c|c|c|}
\hline & \multicolumn{3}{|c|}{ High Parental Attachment } \\
\hline & $\%$ & Phi or Cramer's V & $\mathrm{N}$ \\
\hline Independent & $88.6^{* * *}$ & -.051 & 1226 \\
\hline Not Independent & 91.9 & & 3140 \\
\hline \multicolumn{4}{|l|}{ Controls } \\
\hline Gender & & & \\
\hline Females & $89.3^{* * *}$ & -.064 & 2304 \\
\hline Males & 92.9 & & 2063 \\
\hline Race & & & \\
\hline White & $81.0^{* * *}$ & .039 & 2324 \\
\hline Black & 78.2 & & 948 \\
\hline Hispanic & 76.2 & & 367 \\
\hline Asian & 72.1 & & 146 \\
\hline Native Am. & 74.0 & & 79 \\
\hline Family Structure & & & \\
\hline Non-divorced & $84.1^{* * *}$ & 107 & 261 \\
\hline Divorced & 71.3 & & 2401 \\
\hline Enrollment Status & & & \\
\hline Not enrolled & $90.4 * *$ & .036 & 3323 \\
\hline Enrolled & 92.8 & & 1037 \\
\hline Family SES & & & \\
\hline$<$ HS Diploma & $89.1 *$ & .048 & 488 \\
\hline HS Diploma/GED & 89.4 & & 1125 \\
\hline$B A / B S$ & 92.7 & & 800 \\
\hline$>B A / B S$ & 91.9 & & 693 \\
\hline Age & $\begin{array}{l}\text { Mean } \\
21.84^{* * *}\end{array}$ & & $\begin{array}{l}\text { Range } \\
18-27\end{array}$ \\
\hline Marker Completion & 2.82 & & $0-5$ \\
\hline
\end{tabular}

Source: The National Longitudinal Study of Adolescent Health, Wave 1 


\section{Independence}

The dependent variable in this study was operationalized as living away from parents, which this study refers to as "independence." Half of the respondents in this sample live in their own place (apartment, house or trailer, for instance) as depicted in Figure 4.3 below. The next largest group consists of those who live with their parents or $39 \%$ of the sample. The final eleven percent of the sample live either in another person's home, in group-quarters, or “other” arrangement.

Figure 4.3. Living Arrangements of Emerging Adults

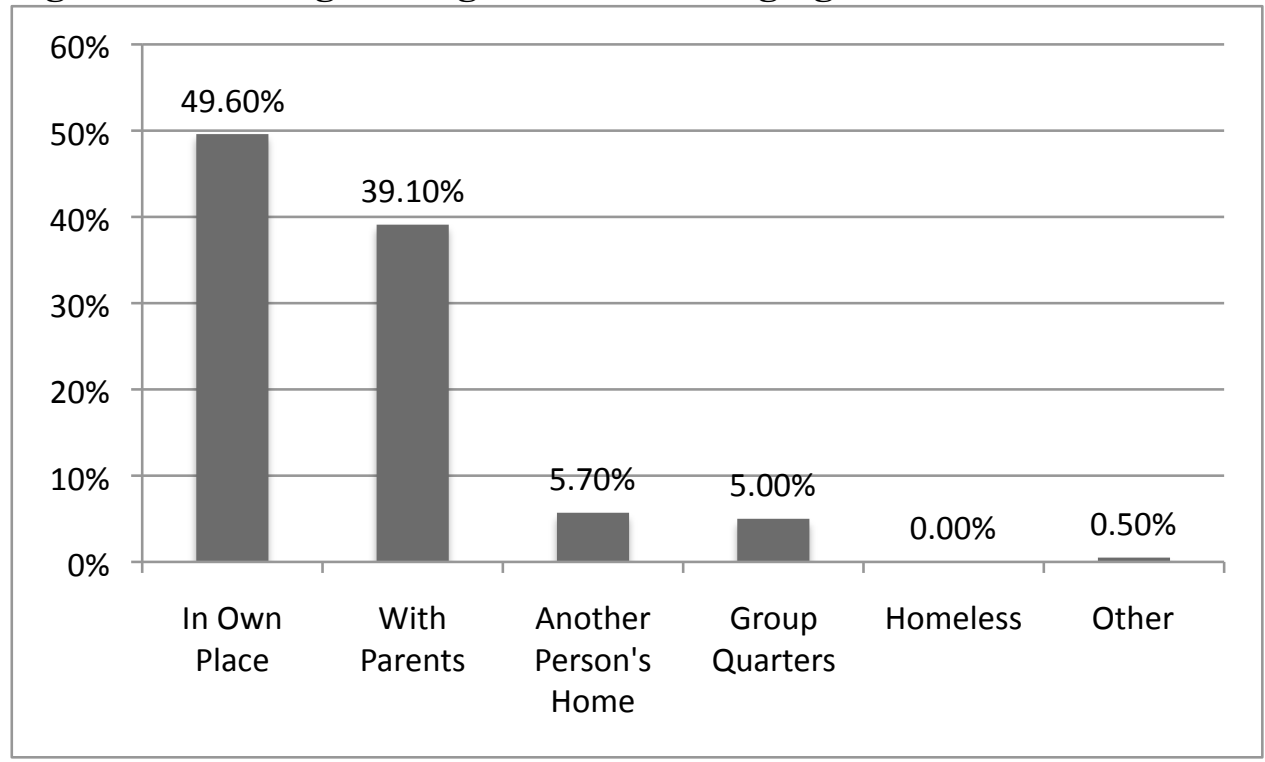

Source: The National Longitudinal Study of Adolescent Health, Wave 3, 2001-2002 $\mathrm{N}=4881$

Focusing first on bivariate analyses in Table 4.2 below, cross tabulation results indicate that there respondents with lower levels of attachment are more likely to be independent than their more highly attached peers $(\mathrm{p}<.001$, Phi=-.078). This finding runs in opposition to the hypothesis that higher attachment will predict independence. 
Table 4.2. Independence, by All Independent Variables

\begin{tabular}{|c|c|c|c|}
\hline & \multicolumn{3}{|c|}{ Independent } \\
\hline & $\%$ & Phi or Cramer's V & $\mathrm{N}$ \\
\hline Parental Attachment & & & \\
\hline High Attachment: W1 & $30.2 * * *$ & -.078 & 1320 \\
\hline Low Attachment: W1 & 42.9 & & 186 \\
\hline Controls & & & \\
\hline Gender & & & \\
\hline Females & $53.1 * * *$ & -.074 & 1395 \\
\hline Males & 45.7 & & 1028 \\
\hline Race & & & \\
\hline White & $33.5 *$ & .048 & 961 \\
\hline Black & 30.3 & & 367 \\
\hline Hispanic & 30.9 & & 149 \\
\hline Asian & 23.6 & & 48 \\
\hline Native Am. & 31.5 & & 34 \\
\hline Enrollment Status & & & \\
\hline Not enrolled & $51.9 * * *$ & -.085 & 1950 \\
\hline Enrolled & 41.8 & & 467 \\
\hline Degree Attainment & & & \\
\hline No Degree & $47.6 * * *$ & .116 & 2052 \\
\hline Has Degree & 65.7 & & 369 \\
\hline & & Gamma & Range \\
\hline Age & $21.84 * * *$ & .021 & $18-27$ \\
\hline Family SES & 07.03 & .003 & $1-10$ \\
\hline$* \mathrm{p}<.05, * * \mathrm{p}<.01, * * * \mathrm{p}<$ & & & \\
\hline
\end{tabular}

Source: National Longitudinal Study of Adolescent Health, Wave 1 and 3. W1 = Wave 1

When sex is considered, cross tabulation results indicate that females were more independent than their male peers $(\mathrm{p}<.001$, Phi $=-.074)$. This confirmed findings from Rumbaut (2006), in which he describes 2000 U.S. Census data, indicating that females from ages 18 to 34 are statistically more likely to live on their own. The research on gender and independence is conflicted. When Hill and Hozer (2007) examine gender and race together, they found that Hispanic males and Black females are more likely to live at home rather than independently. The current study 
examined these two variables together and found that combining race and gender did not significantly change the net effect of independence. Therefore, the final models maintained race and gender as separate variables.

While half of the sample is living independently, these individuals are more likely to be older. Hill and Hozer (2007) cited in their research that $57 \%$ of individuals ages twenty to twenty-two still lived at home. This is fairly consistent with the present research findings that show $65 \%$ of twenty-year-olds still live at home and $44 \%$ of twenty-two-year-olds also live at home, see Figure 4.4 below.

Figure 4.4. Independence, By Age

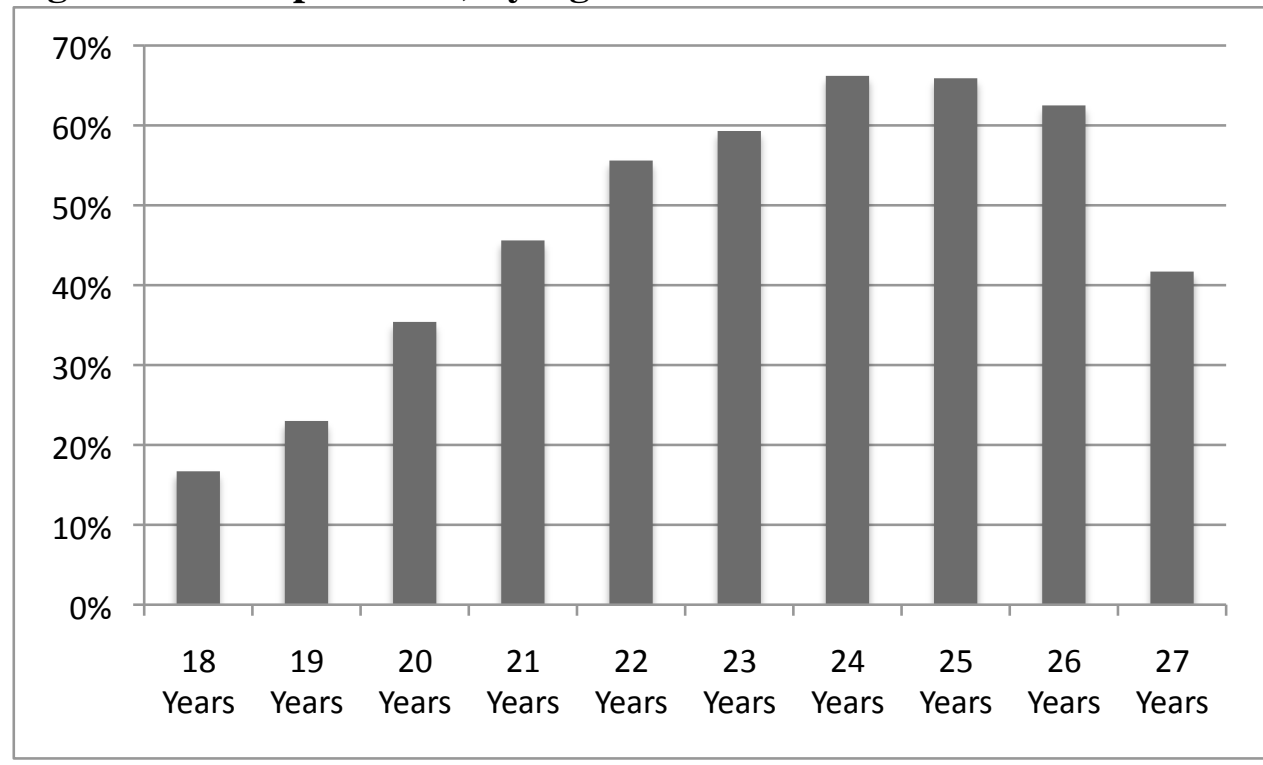

Source: The National Longitudinal Study of Adolescent Health, Wave 3, 2001-2002 Note: 18 year olds $n=36,19$ year olds $n=540,20$ year olds $n=766,21$ year olds $n=801$, 22 year olds $n=877,23$ year olds $n=833,24$ year olds $n=746,25$ year olds $n=229$, 26 year olds $n=40,27$ year olds $n=12$

The percent independent tapers off in the older age groups, as seen in the age groups of 26-year-olds and 27-year-olds above. This data is a snapshot in time and therefore cannot measure the revolving door nature of independence, however it could be 
plausible that individuals in these older age groups may have initially left the nest only to return once again, as suggested by Goldscheider et al. (1993)

As predicted by previous studies (Hill and Hozer 2007), individuals who had completed their bachelor's degree had statistically significant higher rates of independence $(65.7 \%)$ than those without degrees $(47.6 \%)(\mathrm{p}<.001, \mathrm{Phi}=-.116) . \quad$ In economic terms, the most recent U.S. Census data report that individuals with a degree make higher wages than those without a degree (Day and Nuberger 2002). In this sample individuals with degrees lived independently, perhaps because of their economic circumstances.

Finally, individuals who were not currently enrolled in a 4-year college or university were more likely to be independent ( $<<.001$, Phi=-.085). While $51.9 \%$ of individuals not enrolled in a college or university were independent, only $41.8 \%$ of their college-bound peers were independent. This fact could be attributed to the fact that those not enrolled may already have a degree and, as previously mentioned, are more likely to be independent. However, another possible explanation is that those not enrolled in college have more time to work and therefore are able to afford living on their own. 


\section{MULTIVARIATE ANALYSES}

After a detailed descriptive analysis of social background characteristics by attachment and independence, a series of logistic regressions was estimated to determine the effect parental attachment has on being independent. Covariates were entered one at a time to test the hypothesis that high parental attachment in youth is a positive predictor of independence in emerging adulthood, net of important control variables. Analysis begins by predicting independence with the inclusion of only parental attachment (Model I). In an effort to control for the social background effects, the following models then add age (Model II), gender (Model III), family SES (Model IV), race (Model V), school attendance status (Model VI), and degree attainment (Model VII). The purpose of modeling the regressions in this manner was to determine the effect parental attachment has on independence while controlling for other variables.

Table 4.3 presents the resulting odds ratios from predicting physical independence. Contrary to hypothesis one, parental attachment has a weak and statistically significant negative relationship with independence (Model I). Individuals with high levels of parental attachment are $20 \%$ less likely to be independent in emerging adulthood than are individuals with low levels of parental attachment $(\mathrm{OR}=.80, \mathrm{p}<.001)$. The relationship between attachment and independence is notably weaker than the relationship between age and independence. However, this weak negative relationship persists across all seven models with statistical significance. 
Parental attachment has a very low explanatory value (Naglekerke $\left.\mathrm{R}^{2}=.007\right)$, which indicates that this variable explains less than $1 \%$ of the variables that predict independence.

In the second model, age is added as a control variable. By comparing the odds ratio for parental attachment and independence in Model I (.80) to that in Model II (.86), we see that age explains some of the relationship between parental attachment and independence. Model II also shows that age helps considerably to strengthen the model (Naglekerke $\mathrm{R}^{2}=.097$ ). When age is added in Model II, there is a net change of .086 in the $\mathrm{R}^{2}$. Age strengthens the models more than any other variable, which indicates that it has the greatest positive effect on independence. This is consistent with previous research that also determined age to be a positive predictor of independence (Hill and Hozer 2007, Rumbaut 2004).

In Model III, gender is added to the model. Like age, it contributes to the overall strength of the model (Naclekerke $\mathrm{R}^{2}=.097$ ). Gender also explains some of the effect parental attachment had on independence, as the odds ratio for parental attachment changes from .86 to .88 . However, gender does not mediate the relationship between parental attachment and independence with the same magnitude that age does (Model II).

Model IV adds family SES as a controlling factor in predicting independence. The results indicate that family SES is not a significant factor and does not change the odds ratio of parental attachment. This result is in contrast to previous research that 
found that individuals from lower incomes were more likely to be independent than those from higher incomes (Hill and Hozer 2007).

Model $\mathrm{V}$ adds race, or being White, to the equation, which results in an odds ratio of $1.10(\mathrm{p}<.05)$. Race does not Help explain any of the effect of parental attachment on independence. However, the statistical significance of race in this model confirms the findings of Hill and Hozer (2007) that being White, relative to all other race/ethnic groups, is a significant predictor of independence.

The next model adds non-enrollment in a 4-year college or university to the equation. Like race, this variable is statistically significant ( $\mathrm{p}<.001)$, but it does not have an impact on the odds ratio of parental attachment; which continues to have a weak and negative prediction on independence.

Model VII is the full model that includes parental attachment and all of the control variables. This final model adds the attainment of a Bachelor's degree. As with previous models, attaining a Bachelor's degree does not explain away any of the effect that parental attachment has on becoming independent. In general, the results in the final model for independence are low (Naglekerke $\mathrm{R}^{2}=.124$ ), explaining about $12 \%$ of the variation in becoming independent.

In summary, when we observe parental attachment across all seven models we see that it remains a statistically significant factor in predicting independence $(\mathrm{OR}=$ $.88, \mathrm{p}<.001)$. While both age and gender explain some of the effect of parental attachment, as observed in Model II $(\mathrm{OR}=.86)$ and Model III $(\mathrm{OR}=.88)$, the effect of 
parental attachment persists as a weak yet statistically significant predictor in determining independence among emerging adults. This indicates that while controlling for variables that previous research indicates are also positive predictors of independence, parental attachment has a negative impact rather than the positive impact that was hypothesized.

Table 4.3. Estimated Odds Ratios Predicting Independence

\begin{tabular}{|c|c|c|c|c|c|c|c|}
\hline & \multicolumn{7}{|c|}{ Models } \\
\hline Variables & I & II & III & IV & $\mathrm{V}$ & VI & VII \\
\hline $\begin{array}{l}\text { Parental } \\
\text { Attachment }\end{array}$ & $.80 * * *$ & $.86 * * *$ & $.88 * * *$ & $.88 * * *$ & $.88 * * *$ & $.88 * *$ & $.88 * *$ \\
\hline Age & & $1.38 * * *$ & $1.39 * * *$ & $1.39 * * *$ & $1.39 * * *$ & $1.33 * * *$ & $1.37 * * *$ \\
\hline Female & & & $1.31 * * *$ & $1.31 * * *$ & $1.31 * * *$ & 1.35 & $1.37 * * *$ \\
\hline Family SES & & & & 1.02 & 1.00 & 1.00 & 1.00 \\
\hline White $^{l}$ & & & & & $1.10 *$ & $1.09 *$ & $1.09 *$ \\
\hline $\begin{array}{l}\text { Not In 4-Year } \\
\text { College/Univ. } \\
\text { Has } \\
\text { Bachelor's }\end{array}$ & & & & & & $1.48 * * *$ & $\begin{array}{l}1.46 * * * \\
1.63 * * *\end{array}$ \\
\hline Constant & .07 & -7.29 & -7.69 & -7.69 & -7.79 & -6.85 & -7.30 \\
\hline $\begin{array}{l}\text { Number of } \\
\text { Observations }\end{array}$ & 4800 & 4800 & 4800 & 4781 & 4781 & 4774 & 4773 \\
\hline Nagelkerke $\mathrm{R}^{2}$ & .007 & .093 & .097 & .098 & .099 & .118 & .124 \\
\hline $\begin{array}{l}\text { Source: The Nati } \\
{ }^{*} \mathrm{p}<.05, * * \mathrm{p}<.01, \\
{ }^{1} \text { Note: Omitted ca }\end{array}$ & $\begin{array}{l}\text { nal Longit } \\
* * \mathrm{p}<.001 \\
\text { egory for }\end{array}$ & $\begin{array}{l}\text { dinal Study } \\
\text { ach variable }\end{array}$ & $\begin{array}{l}\text { f Adolesc } \\
\text { is all other }\end{array}$ & $\begin{array}{l}\text { t Health, V } \\
\text { ces }\end{array}$ & ve 3,2001 - & 2002 & \\
\hline
\end{tabular}




\section{CHAPTER V \\ DISCUSSION AND CONCLUSION}

\section{Summary}

The analyses presented in this study show that parental attachment in youth has a slightly negative impact on becoming an independent adult. While this study shows that emerging adults exhibit highly attached sentiments toward their parents, its predictive value for increasing levels of independence is not clearly established. This unconfirmed hypothesis seems to suggest that there may be a slightly negative effect of being highly attached to parents. The following sections will discuss in detail these and other findings.

\section{Discussion- Parental Attachment}

Why might parental attachment have a slightly negative impact on becoming independent? This question directs this research back to both attachment literature and independence literature. This study hypothesized that an attached child would feel a secure push and pull as suggested by Bowlby $(1969,1973,1980)$ and Hirschi (1969). The findings indicate that the opposite may be true. An attached child is slightly less likely to become independent. Perhaps there has been a generational parenting shift in attachment behaviors than were measured in the 1960s, 1970s, and 1980s. Attachment in these decades was perceived in a positive light. Could over attachment be a problematic contemporary phenomenon? The sample population was 
studied in 1994, a full two decades or more after Bowlby's initial theory was postulated. Perhaps parenting styles have changed in the course of this time and overprotective parents are causing more dependence in children rather than cultivating independence. This is an issue that merits further investigation and would be an excellent topic for future research.

While parental attachment may not have been a strong predictor of independence in these models as hypothesized, the variation found in levels of attachment merits recognition. In general, highly attached individuals were most likely to be male, non-Hispanic Whites, from stable families. Additionally, families with parental educations beyond the bachelor's degree showed significantly less attachment than those with less education.

The level of attachment by gender is of particular interest because it contrasts with previous studies that found females to be more highly attached to parents (Thornton et al. 1995; Sorokuo and Weissbrod 2005). This result could be indicative of the low numbers of cases and limited sampling technique used in the Sorokuo and Weissbrod study $(\mathrm{N}=88)$, which were derived from one college campus. The strength of the present study is that there are many more cases drawn from a national sample, which allows for greater generalizability in the findings. The study by Thornton and colleagues used a sample of interviews gathered in 1980 and 1985. The sample in the current study was conducted in 2007, a full twenty years later than the earlier study. This could indicate a cultural shift in the gendered nature of attachment; perhaps males are adopting more affective responses than they did two decades ago. This also merits 
further explanation as family researchers investigate the changing norms in parentchild relationships.

With regard to SES, the findings of this study indicate that as parental education increases, so does attachment. This confirms Bogardi's (2001) study that higher SES families show higher parental attachment. However, in light of the negative findings the current study reports regarding the effect of attachment on becoming independent, this might not be good news for individuals with more education. These findings could indicate that the more education a parent has, the longer they can expect their child to live at home. This assumption merits further investigation that would focus on the parent-child relationship by class.

The final parental attachment variation is that of race. The current study indicates that being White or Hispanic, versus being of any other race had small positive statistical significance in predicting attachment. Kenny (2006) discusses that the psychological literature is lacking in terms of investigating the effect race has on attachment. Sociologists who examine control theory have found that parental attachment cannot be causally linked to race (Bogard 2005, Magnino 2009). However, the question of race and parental attachment is not one that has been investigated thoroughly by either psychologists or sociologists. The current study also does not examine ethnicity as Portes and Rumbaut (2001) have done, which could prove to be a fruitful investigation. The findings in the present study hint that there may be some racial variations in attachment, but further research would be needed to affirm any direct correlations. 


\section{Discussion - Independence}

In the current study, the number of individuals who are independent from their parents is equal to those who remain in the nest. The same can be said for parental attachment, as highly attached individuals are no more likely to be independent than their less attached peers, contrary to the assertion in hypothesis seven. The individuals who are most likely to be independent are older, female, White, not enrolled in a 4year college or university, and have completed their bachelor's degree. These findings are all consistent with previous research (Hill and Hozer 2007; Rumbaut 2006).

Future research should consider whether or not becoming independent merits achieving at all. People in other societies and at earlier periods of history have seen that being independent from parents as a negative outcome for society as a whole (McLoyd et al. 2000). What is the experience of these families that sustain multiple generations under one roof? Is there a new form of independence that is appropriate for a new generation of families? Researchers Bellah et al. (1985/2007) explore the discussion of individualism in America and suggest that it is individualism that is corroding American communities and social sustainability. Perhaps the question for a new study should investigate how interdependent parent-child relationships might contribute to healthy adulthood for the next generation rather than independent children. This could mean a new way of conceptualizing the process of becoming an adult in the U.S. For example, in times of global economic hardship it might be financially advantageous for multiple families to live together. This could, in turn, promote stronger familial connections. This certainly merits further investigation. 


\section{Limitations}

An important limitation in this study is the possibly insufficient operationalization of attachment. First, this study uses self-reported feelings of attachment to parents as a variable. Attachment is a complex reality that may be insufficiently measured by two questions. While many studies in sociology use similar measures (Haynie 2004, Magnino 2009), psychology uses instruments, such as the Inventory of Parental and Peer Attachment by Armsden and Greenberg (1987) or the Parental Attachment Questionnaire by Maureen Kenny (1985), that operationalize attachment with more robust measures. These questionnaires however have not been applied to large nationally representative sample populations, such as the Add Health data. The ability to test a full measure of parental attachment may be contingent on attaining a greater pool of cases using a fuller measure of attachment.

Second, the dataset does not give information on respondents' attachments to non-parents using the same measures. Initially, the internal working model that Ainsworth (1989) and Bowlby (1988) described may be present in relationships outside of that parent-child dyad. While the present research conceptualized attachment using all possible parental figures, other people may play a role in providing attachment to an individual, such as a sibling, clergy or other mentor. While Bogard (2005) found that there was no evidence that other adults could substitute for lack of attachment from parents, research in religion indicates that some individuals who expressed an extreme religious conversion did so out of a parental attachment deficit (Granqvist and Hagekull 1999). This points to the notion that individuals may 
be able to find attachment in other people or entities, such as a religious god. The present data does not conceptualize attachment to other figures such as siblings, partners, and certainly not a god-figure. Future research needs to investigate multiple sources of attachment to other besides parents and how the presence of such attachments might contribute to an internal working model that produces positive outcomes in all ages of children.

Finally, this study measures a one-time snapshot of independence. It does not measure the revolving door nature of independence that can be found in today's emerging adults. Economic forces or other circumstances sometimes dictate a return to home after an initial departure (Goldscheider et al. 1993). Future research may be able to capture the longitudinal nature of this adulthood marker using the Wave IV data that is not yet available. This question remains a topic for future research.

\section{Conclusion}

It is clear from this study that emerging adults continue to have a strong attachment to their parental figures. The findings from this research cannot prove that these relationships propel the child toward independence or pull them from delinquency as was originally hypothesized. The results do indicate a slightly negative affect of parental attachment on independence in emerging adults. The operationalization of parental attachment may not adequately capture this interaction, which may limit the findings of this study. 
As initially described by Davis (1940), parents and guardians are strong influences on children and their developmental paths. Researchers have explained this through social interaction theories such as parental attachment (Bowlby 1969) and social control (Nye 1958, Durkheim 1961, Hirschi 1969). Our best attempts to understand the nature of this influential relationship are limited by our ability to link relationally causal forces, such as parental attachment. For example, a college student may recognize his or her parent's influence on getting him or her to college through means such as providing academic encouragement, paying for expenses, or even filling out the child's application. But can we truly recognize the relational forces that are at work along the way? The variety of factors could impede independence, thus making it difficult to measure the influence of parental attachment. Perhaps a complimentary approach to this investigation would be to explore the qualitative interpretations of the nature and influence that the parental relationship has on the emerging adult's ability to become independent.

In addition to difficulties in measuring the affective parental relationship, it is equally complicated to recognize forces that cause a child to leave home. While this researcher hypothesizes that a securely attached relationship empowers a child to launch from the nest, a very negative relationship might also cause a child to leave the nest. The data could be indicative of both healthy and unhealthy parental relationships causing a child to leave home. In this light of this spurious effect, a possibility for future research would be to examine the relationship intricacies of individuals who remain in their parents' home well into adulthood. 
In summary, this study indicates that parents of emerging adults clearly are not out of the picture once the child reaches age eighteen and beyond. Most emerging adults, while prolonging their independence, eventually make the transition to a life physically and financially separated from their parents. This transition, however, is not made in a vacuum. The results of this study suggest that independence has been achieved either because of or in spite of the parent-child relationship. This field of study begs further investigation as researchers contribute to society's understanding of how parents can strengthen their emerging adults and encourage a successful transition to independence. 


\section{REFERENCES}

Ainsworth, Mary. 1989. “Attachments Beyond Infancy.” American Psychologist, 44, 709-716.

Ainsworth, Mary, and M. Blehar, E. Waters and S. Wall. 1978. Patterns of Attachment: A Psychological Study of the Strange Situation. Hillsdale, NJ: Lawrence Erlbaum.

Ambert, Anne-Marie, 2005. “Is Marriage Being Replaced by Cohabitation?” Journal of Marriage and the Family.

Amato, P. r. and A. Booth. 1996. "A Prospective Study of Divorce and Parent-child Relationships." Journal of Marriage and the Family, 58:356-365.

Arnett, Jeffery Jensen, 2004. "Emerging Adulthood: The Winding Road from the Late Teens through the Twenties."

Bearman, Peter and James Moody. 2004. "Suicide and Friendships Among American Adolescents." American Journal of Public Health, 94:89-96.

Bell, Lisa, Gary Burtless, Janet Gornick, and Timothy Smeeding. 2007. "Failure to Lunch: Cross-National Trends in the Transition to Economic Independence." In Danziger, Sheldon and Cecilia Elena Rouse (Eds.) 2007. The Price of Independence, New York: Russell Sage Foundation.

Bellah, Robert, Richard Madsen, William Sullivan, Ann Swidler, and Stephen Tipton. 1985/2007. Habits of the Heart: Individualism and Commitment in American Life. Berkeley, CA: University of California Press.

Blos, P. 1979. The Adolescent Passage: Developmental Issues. New York: International Universities Press.

Bogard, Kimber. 2005. “Affluent Adolescents, Depression, and Drug Use: The Role of Adults in their Lives." Adolescence, 40:281-306.

Bowlby, John. 1988. A Secure Base: Parent-child Attachment and Healthy Human Development. New York: Basic Books.

Bowlby, John. 1980. Loss, Sadness and Depression, Vol. III. New York: Basic Books.

Bowlby, John. 1973. Attachment and Loss, Vol.II: Separation. New York: Basic Books. 
Bowlby, John. 1969, 1982 second ed. Attachment and Loss, Vol. I: Attachment. New York: Basic Books.

Bucx, Freek and Frits van Wel. 2008. "Parental Bond and Life Course Transitions from Adolescence to Young Adulthood." Family Therapy, 35:109-126.

Carranza, Laura V. , Peter R. Kilmann and Jennifer M. C. Vendemia. 2009. "Links Between Parent Characteristics and Attachment Variables of College Students of Parental Divorce." Adolescence, 174: 253-271.

Cernkovich, Stephen and Peggy Giordano. 1987. "Family Relationships and Delinquency." Criminology, 25:295-321.

Danziger, Sheldon and Cecilia Elena Rouse, Eds. 2007. The Price of Independence: The Economics of Early Adulthood. New York: Russell Sage Foundation.

Davis, Kingsley. 1940. "Extreme Social Isolation of a Child.” American Journal of Sociology, 45(4): 554-65.

Day, Jennifer and Eric Newburger. 2002. "The Big Payoff: Educational Attainment and Synthetic Estimates of Work-Life Earnings." U.S. Census Current Population Reports.

Demick, Jack and Carrie Andreoletti, Eds. 2003. Handbook of Adult Development. New York: Springer.

Durkheim, Emile. 1961. Moral Education, trans. Everett K. Wilson and Herman Schnurer, New York: The Free Press.

Eggebeen, David and Jeffrey Dew. 2009. "the Role of Religion in Adolescence for Family Formation in Young Adulthood." Journal of Marriage and Family 71:108-121.

Fisher, William A., Jeffrey D. Fisher, and J.J. Rye. 1995. "Understanding and Promoting AIDS-Preventative Behavior: Insights from the Theory of Reasoned Action." Health Psychology 14:255-264.

Furstenberg Jr., Frank F., Sheela Kennedy, Vonnie C Mcloyd, Rubèn G. Rumbaut and Richard A. Settersten. 2004. "Growing Up is Harder to Do.” Contexts, 3(3):33-41.

Furstenberg, Frank F. Jr., Ruben G. Rumbaut, and Richard A. Settersten, 2005. “On the Frontier of Adulthood: Emerging Themes and New Directions." In Settersten, Richard A., Frank F. Furstenberg Jr. and Ruben Rumbaut, Eds. 2005 On the Frontier of Adulthood: Theory Research and Public Policy, Chicago: University of Chicago Press. 
Fussell, Elizabeth and Frank F. Furstenberg Jr., 2005. "The Transition to Adulthood During the Twentieth Century." In Settersten, Richard A., Frank F. Furstenberg Jr. and Ruben Rumbaut, Eds. 2005 On the Frontier of Adulthood: Theory Research and Public Policy, Chicago: University of Chicago Press.

Gillmore, Mary Rogers, Matthew E. Archibald, Diane M. Morrison, Anthony Wilsdon, Elizabeth A. Wells, Marilyn J. Hope, Deborah Nahom, and Elise Murowchick. 2002. "Teen Sexual Behavior: Applicability of the Theory of Reasoned Action.” Journal of Marriage and Family, 64:885-897.

Giordano, Peggy, Stephen Cernkovich and Alfred DeMaris. 1993. "The Family and Peer Relations of Black Adolescents." Journal of Marriage and the Family, 55:277-287.

Goldscheider, Frances, Arland Thornton and Linda Young-DeMarco. 1993. "A Portrait of the Nest-leaving Process in Early Adulthood," Demography, 30:683-699.

Gandqvist, Pehr and Berit Hagekull. 1999. "Religiousness and Perceived Childhood Attachment: Profiling Socialized Correspondence and Emotional Compensation." Journal for the Scientific Study of Religion. 39(2):254-273.

Gunnoe, Marjorie L. and Kristin A. Moore. 2002. "Predictors of Religiosity Among Youth Aged 17-22: A Longitudinal Study of the National Survey of Children." The Journal for the Scientific Study of Religion, 41:613-622.

Haynie, Dana, Darrell Steffensmeier and Kerryn Bell. 2007. "Gender and Serious Violence: Untangling the Role of Friendship Sex Composition and Peer Violence." Youth Violence and Juvenile Justice. 5:235-253.

Hinderlie, H. and Maureen Kenny. 1999. "Parental attachment, Social Support and College Adjustment Among Black College Students on White Campuses." Presented at the $107^{\text {th }}$ annual convention of the APA, Boston, MA, found in Maureen Kenny 2002.

Hirschi, Travis. 1969. Causes of Delinquency. Los Angeles, CA: University of California Press.

Hill, Carolyn J. and Harry Holzer. 2007. “Labor Market Experiences and Transitions to Adulthood." In Danziger, Sheldon and Cecilia Elena Rouse (Eds.) 2007. The Price of Independence, New York: Russell Sage Foundation.

Horn, Laura and Rachael Berger. 2004. "Is College Persistence on the Rise? Changes in 5-Year Degree Completion and Postsecondary Persistence Rates Between 1994 and 2000." The National Center for Education Statistics, U.S. Department of Education Institute of Education Sciences. 
Juang, L. P., R. K. Silbereisen, and M Wiesner, 1999. "Predictors of Leaving Home in Young Adults Raised in Germany: A Replication of the 1991 Study." Journal of Marriage and Family. 61:505-515.

Kenny, Maureen. 1987. "The Extent and Function of Parental Attachment Among First-year College Students.” Journal of Youth and Adolescence. 16:17-27.

Kenny, Maureen E and Kenneth G. Rice. 1995. “Attachment to Parents and Adjustment in Late Adolescent College Students: Current Status, Applications, and Future Considerations." The Counseling Psychologist, 23(3):433-456.

Kenny, Maureen E. and Catherine E. Barton. 2002. "Attachment Theory and Research: Contributions for Understanding Late Adolescent and Young Adult Development." Pp. 371-389 in Handbook of Adult Development, edited by Jack Demick and Carrie Andreoletti. New York, NY: Springer.

Kenny, Maureen E. and Selcuk R. Sirin. 2006. "Parental Attachment, Self-Worth, and Depressive Symptoms Among Emerging Adults.” Journal of Counseling and Development, 84:61-71.

Kobak, R. and a. Sceery. 1988. "Attachment in Late Adolescence: Working Models, Affect Regulation, and Representation of Self and Others." Child Development. 59:135-146.

Lareau, Annette. 2003. Unequal Childhoods: Class, Race and Family Life. Los Angeles, CA: University of California Press.

Leavin, Jack, James Alan Fox and David R. Forde. 2010. Elementary Statistics in Social Research, 11ed. Boston, MA: Allyn and Bacon.

Luster, Tom, and Stephen A. Small. 1994. "Factors Associated with Sexual Risk Taking Behaviors among Adolescents." Journal of Marriage and the Family. 56:622-632.

Magnino, William. 2009. "The Downside of Social Closure: Brokerage, Parental Influence, and Delinquency Among African American Boys.” Sociology of Education, 82:147-172.

Mattanah, J. F. Hancock, G., \& Brand, B. L. 2004. "Parental Attachment, SeparationIndividuation, and College Student Adjustment: A Structural Equation Analysis of Mediational Effects.” Journal of Counseling Psychology, 51, 213225.

McLoyd, Vonnie C., Anna Mari Cauce, David Takeuchi, and Leon Wilson. 2000. "Marital Processes and Parental Sociolization in Families of Color: A Decade Review of Research.” Journal of Marriage and Family 62: 1070-93. 
Mollenkopf, John, Mary C. Waters, Jennifer Holdaway, and Philip Kasinitz. 2005. "The Ever-winding Path: Ethinic and Racial Diversity in the Transition to Adulthood." In Settersten, Richard A., Frank F. Furstenberg Jr. and Ruben Rumbaut, Eds. 2005 On the Frontier of Adulthood: Theory Research and Public Policy, Chicago: University of Chicago Press.

Mouw, Ted, 2005. "Sequences of Early Adult Transitions: A Look at Variability and Consequences” In Settersten, Richard A., Frank F. Furstenberg Jr. and Ruben Rumbaut, Eds. 2005 On the Frontier of Adulthood: Theory Research and Public Policy, Chicago: University of Chicago Press.

Nye, Ivan F. 1958. Family Relationships and Delinquent Behavior. Westport CT: Greenwood Press.

Osgood, Wayne, Gretchen Ruth, Jacquelynn Eccles, Janis Jacobs and Bonnie Barber. 2005. "Six Paths to Adulthood: Fast Starters, Parents without Careers, Educated Partners, Educated Singles, Working Singles, and Slow Starters.” In Settersten, Richard A., Frank F. Furstenberg Jr. and Ruben Rumbaut, Eds. 2005 On the Frontier of Adulthood: Theory Research and Public Policy, Chicago: University of Chicago Press.

Pearce, A.. 2007. "Religious Identity and Family Ideologies in the Transition to Adulthood." Journal of Marriage and Family 69:1227-1243.

Portes, Alejandro and Patricia Fernandez-Kelly, 2008. "No Margin for Error: Educational and Occupational Achievement among Disadvantaged Children of Immigrants." Annals, AAPSS, 620:12-36.

Portes, Alejandro and Ruben Rumbaut. 2001. Legacies: The Story of Immigrant Second Generation. Los Angeles, CA: University of California Press.

Rankin, Joseph, and Roger Kern. 1994. "Parental Attachments and Delinquency." Criminology 32:495-515.

Rice, Kenneth G. and Teddi J. Young. 1997. “Attachment to Parents, Social Competence and Emotional Well-Being: A Comparison of Black and White Late Adolescents." Journal of Counseling Psychology. 44:89-101.

Rumbaut, Rubén J. 2004. "Young Adults in the United States: A Profile." Working paper for the Research Network on Transition to Adulthood and Public Policy funded by the MacArthur Foundation.

Rumbaut, Ruben J. and Alejandro Portes, 2006. "The Second Generation in Early Adulthood: New Findings from the Children of Immigrants Longitudinal Study." Migration Information Source of Migration Policy Institute. 
Schoeni, Robert F. and Karen E. Ross. 2005. "Material Assistance from Families During the Transition to Adulthood." In Settersten, Richard A., Frank F. Furstenberg Jr. and Ruben Rumbaut, Eds. 2005 On the Frontier of Adulthood: Theory Research and Public Policy, Chicago: University of Chicago Press.

Schultheiss, D. E. P. and D. L. Blustein. 1994. "Role of Adolescent-parent Relationships in College Student Development and Adjustment." Journal of Counseling Psychology. 41:248-255.

Settersten, Richard. 2007. "Passages to Adulthood: Linking Demographic Change and Human Development.” Eur. J Population, 23:251-272.

Shanahan, Michael, Erik Porfeli, Jeylan Mortimer and Lance Erickson, 2005. "Subjective Age Identity and the Transition to Adulthood: When Do Adolescents Become Adults?" In Settersten, Richard A., Frank F. Furstenberg Jr. and Ruben Rumbaut, Eds. 2005 On the Frontier of Adulthood: Theory Research and Public Policy, Chicago: University of Chicago Press.

Silverstein, Merril, Vern L. Bengtson and Leora Lawton. 1997. "Intergenerational Solidarity and the Structure of Adult Child-Parent Relationships in American Families." American Journal of Sociology. 103:429-460.

Schoeni, Robert and Karen Ross. 2005. "Material Assistance from Families During the Transition to Adulthood." In Settersten, Richard A., Frank F. Furstenberg Jr. and Ruben Rumbaut, Eds. 2005 On the Frontier of Adulthood: Theory Research and Public Policy, Chicago: University of Chicago Press.

Sorokou, Christina and Carol S. Weissbrod. 2005. "Men and Women's Attachment and Contact Patterns with Parents During the First Year of College." Journal of Youth and Adolescence 34:221-228.

Stoops, Nicole, 2004. "Educational Attainment in the United States: 2003." Current Population Reports, U.S. Census Bureau: Economics and Statistics Administration.

Stryker, S. 1968. "Identity Salience and Role Performance: The Relevance of Symbolic Interaction Theory for Family Research." Journal of Marriage and the Family. 30: 558-564.

Sweet, Stephen A. and Karen Grace-Martin. 2008. Data Analysis with SPSS: A First Course in Applied Statistics, $3^{\text {rd }}$ Ed. Boston: Pearson.

Taub, Deborah J. 1997. "Autonomy and Parental Attachment in Traditional-age Undergraduate Women." Journal of College Student Development. 38:645655. 
U.S. Census Bureau, “America's Families and Living Arrangements: 2008” retrieved on October 19, 2009, http://www.census.gov/population/www/socdemo/hhfam/cps2008.html.

U.S. Department of Health and Human Services, "The HHS US Poverty Guidelines." Retieved on October 19, 2009, http://aspe.hhs.gov/poverty/09poverty.shtml.

Wintre, Maxine G. and Mordechai Yaffe. 2000. "First-year Students' Adjustment to University Life as a Function of Relationships with Parents." Journal of Adolescent Research. 15:9-37.

Yelowitz, Aaron. 2007. "Young Adults Leaving the Nest: The Role of the Cost of Living." In Danziger, Sheldon and Cecilia Elena Rouse, Eds. 2007. The Price of Independence: The Economics of Early Adulthood. New York: Russell Sage Foundation. 
Appendix: Variable Construction Items

\section{Independence}

Where do you live now? That is, where do you stay most often?

\section{Attachment}

Wave I

How close do you feel to your current residential mother?

$$
\begin{aligned}
& 1=\text { not close at all } \\
& 2=\text { not very close } \\
& 3=\text { somewhat close } \\
& 4=\text { quite close } \\
& 5=\text { extremely close }
\end{aligned}
$$

Do you think your mother cares for you?

$$
\begin{aligned}
& 1=\text { strongly disagree } \\
& 2=\text { disagree } \\
& 3=\text { neither agree or disagree } \\
& 4=\text { agree } \\
& 5=\text { strongly agree }
\end{aligned}
$$

How close do you feel to your current residential father?

Do you think your father cares for you?

\section{Wave III}

How close do you feel to your previous residential mother?

Most of the time, she is warm and loving toward you.

How close do you feel to your previous residential father?

Most of the time, he is warm and loving toward you. 